\title{
Leveraging Smart Meter Data for Economic Optimization of Residential Photovoltaics under Existing Tariff Structures and Incentive Schemes
}

\author{
Jeremy Everya,, ${ }^{\mathrm{a},} \mathrm{Li} \mathrm{Li}^{\mathrm{a}}$, David G. Dorrell ${ }^{\mathrm{b}}$ \\ ${ }^{a}$ School of Electrical, Mechanical and Mechatronic Systems, Faculty of Engineering and Information Technology, \\ University of Technology Sydney, 81 Broadway, Ultimo, NSW 2007, Australia \\ ${ }^{b}$ School of Electrical, Electronic and Computer Engineering, College of Agriculture, Engineering and Science, \\ University of KwaZulu-Natal, Durban 4041, South Africa
}

\begin{abstract}
The introduction of smart grid technologies and the impending removal of incentive schemes is likely to complicate the cost-effective selection and integration of residential PV systems in the future. With the widespread integration of smart meters, consumers can leverage the high temporal resolution of energy consumption data to optimize a PV system based on their individual circumstances. In this article, such an optimization strategy is developed to enable the optimal selection of size, tilt, azimuth and retail electricity plan for a residential PV system based on hourly consumption data. Hourly solar insolation and PV array generation models are presented as the principal components of the underlying objective function. A net present value analysis of the potential monetary savings is considered and set as the optimization objective. A particle swarm optimization algorithm is utilized, modified to include a penalty function in order to handle associated constraints. The optimization problem is applied to real-world Australian consumption data to establish the economic performance and characteristics of the optimized systems. For all customers assessed, an optimized PV system producing a positive economic benefit could be found. However not all investment options were found to be desirable with at most $77.5 \%$ of customers yielding an acceptable rate of return. For the customers assessed, the mean PV system size was found to be $2 \mathrm{~kW}$ less than the mean size of actual systems installed in the assessed locations during 2015 and 2016. Over-sizing of systems was found to significantly reduce the potential net benefit of residential PV from an investor's perspective. The results presented in this article highlight the necessity for economic performance optimization to be routinely implemented for small-scale residential PV under current regulatory and future smart grid operating environments.
\end{abstract}

Keywords: Photovoltaic system, Smart meter, Dynamic tariff, Mixed-integer non-linear programming, Particle swarm optimization, Net present value analysis

\section{Introduction}

Over the last decade, the solar photovoltaics (PV) industry has undergone significant technological improvement and enormous growth in installed capacity. As market penetration increases for PV, primarily driven by the continued reduction in technology costs, installation incentive schemes will be reduced or removed altogether. In an Australian context, the Solar Bonus Scheme (SBS) and the Small-scale Renewable Energy Scheme (SRES) incentivized the installation of PV through generous feed-in tariffs (FiT) and a cost rebate mechanism

\footnotetext{
${ }^{*}$ Corresponding author

Email address: jeremy. every@student.uts.edu.au (Jeremy Every)

Preprint submitted to Applied Energy
}

respectively. Historically, these incentive schemes encouraged investors to install large PV systems aiming to generate as much energy as possible during peak solar insolation hours. However the SBS in Australia, under which the FiT was initially set to be $60 \mathrm{c} / \mathrm{kWh}$ and later reduced to $20 \mathrm{c} / \mathrm{kWh}$, was closed to new customers in 2011 and officially ended in 2016. Current Australian FiTs are no longer mandated but rather set by individual retailers. As an example, the benchmark range for FiTs in New South Wales was 4.7-6.1 c/kWh in 2015-2016 increasing to 5.5-7.2 c/kWh in 2016-2017 [1], significantly less than those offered under the SBS.

An assessment of the Australian Government Clean 25 Energy Regulator (CER) database [2] revealed a relatively large national average size of $5.11 \mathrm{~kW}$ for new sys- 


\begin{tabular}{|c|c|c|}
\hline \multicolumn{3}{|l|}{ Nomenclature } \\
\hline$\alpha(\cdot), \lambda(\cdot), h(\cdot), \psi(\cdot)$ Penalty function components & $R_{b}$ & Ratio of tilted-plane versus horizontal beam irradiance \\
\hline $\mathrm{PV}$ array tilt angle & $r_{g}$ & Effective real electricity price growth \\
\hline Constriction factor & $r_{\text {deg }}$ & Degradation rate \\
\hline Solar declination and latitude & $r_{\text {eff }}, r_{\text {real }}$ & Effective and real annual discount rates \\
\hline Balance of plant efficiency & $r_{i, n}^{j}, R_{i n}^{j}$ & Sequence of uniformly distributed random numbers \\
\hline $\begin{array}{l}\eta_{m p p}, \eta_{m p p, s t c} \text { Maximum power point efficiency at operating and } \\
\text { standard test conditions }\end{array}$ & $S_{p v}^{i, n}$ & PV system cost \\
\hline $\begin{array}{ll} & \text { standard test conditions } \\
\gamma & \text { PV array azimuth angle }\end{array}$ & $t$ & Number of discounting periods per year \\
\hline $\begin{array}{l}\text { PV array azimuth angle } \\
\text { Maximum power point temperature coefficient }\end{array}$ & \multicolumn{2}{|c|}{ 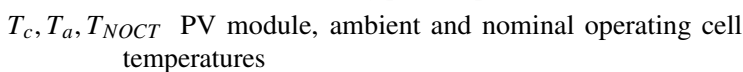 } \\
\hline Solar hour and sunset hour angles & \multicolumn{2}{|c|}{$T_{\text {feed,qdh }}$ PV feed-in tariff } \\
\hline Latitude & \multirow{2}{*}{\multicolumn{2}{|c|}{$\begin{array}{l}T_{\text {grido, } q d h}, T_{\text {grid,qdh }} \text { Grid-imported tariff under lowest cost and al } \\
\text { ternative plans }\end{array}$}} \\
\hline Ground reflectance & & \\
\hline $\begin{array}{l}\text { Beam irradiance angle of incidence and zenith angle } \\
\text { PV module area }\end{array}$ & \multicolumn{2}{|c|}{$\begin{array}{l}T_{s c 0, q d}, T_{s c, q d} \text { Daily supply charge under lowest cost and alterna- } \\
\text { tive plans }\end{array}$} \\
\hline Acceleration coefficients & \multicolumn{2}{|c|}{$U_{i n v}, U_{p v}$ Unit cost of inverter replacement and PV system $(\$ / \mathrm{W})$} \\
\hline $\begin{array}{c}C_{b a s e, q}, C_{p v, q} \text { Electricity cost in period } q \text { without (lowest cost plan) } \\
\text { and with PV installed }\end{array}$ & $v_{i, n}^{j}, x_{i, n}^{j}$ & $\begin{array}{l}\text { Velocity and position of particle } i \text { in dimension } j \& \text { itera- } \\
\text { tion } n\end{array}$ \\
\hline Cost of SRES certificates & $y$ & Year number \\
\hline Day, hour and billing period & $Z$ & Number of PV modules \\
\hline$D_{k} \quad$ Degradation factor & $\mathrm{CDO}$ & Climate Data Online \\
\hline$E_{\text {load, }, q d h}, E_{p v, q d h}$ Load energy and PV generated energy & CER & Clean Energy Regulator \\
\hline Yearly energy consumption & FiT & Feed-in Tariff \\
\hline Optimization constraint functions & LCOE & Levelized Cost of Electricity \\
\hline$G_{T}, I_{T} \quad$ Irradiance and hourly insolation on tilted plane & MIRR & Modified Internal Rate of return \\
\hline$G_{n}^{j}, P_{i, n}^{j} \quad$ Global and personal best positions of particle $i$ in dimen- & NOCT & $\begin{array}{l}\text { Nodified Internal Rate of return } \\
\text { Nominal operating cell temperature }\end{array}$ \\
\hline $\begin{array}{l}\text { Sion } j \& \text { iteration } n \\
\text { n }\end{array}$ & NPV & Net present value \\
\hline$H, H_{b}, H_{d}$ Daily global, beam and diffuse insolation & PSO & Particle swarm optimization \\
\hline $\begin{array}{l}1, I_{b}, I_{d}, I_{o} \text { Hourly global, beam, diffuse \& extra-terrestrial insola- } \\
\text { tion }\end{array}$ & PV & Photovoltaics \\
\hline$i, j, n \quad$ Particle number, particle dimension and iteration number & SBS & Solar Bonus Scheme \\
\hline Dimensionality of the, number of problem constraints, & SGSC & 'Smart Grid, Smart City’ project \\
\hline number of iterations in the solution algorithm & SRES & Small-scale renewable energy scheme \\
\hline$M_{l i f e}, M_{l o c}$ SRES contribution length and location multipliers & STC & Standard test conditions \\
\hline$P_{p v}, P_{p v, r a t} \mathrm{PV}$ output and rated powers & TOU & Time-of-use \\
\hline
\end{tabular}

tems installed between January 2015 and August 2016. However due to closure of the SBS, the newly installed large systems are ineligible for the high mandated FiTs under the SBS and subsequently the payback period is increasingly reliant on the cost savings achieved through self-consumption of PV generated energy.

Current policy is to retain the SRES in the medium term however the magnitude of the effective rebate will 35 be gradually reduced between 2017-2030 [3]. Consequently, a shift in industry practice is required, moving from large PV systems to more economically efficient ones.

The reduction and removal of incentive schemes are 40 not the only disrupting factor to the small-scale PV in- dustry. The penetration and system characteristics of residential PV systems have the potential to be significantly influenced by the introduction of smart meters and other smart grid technologies. Enabled by smart meters, the implementation of new dynamic tariff structures will require due consideration of a customer's temporal energy consumptions habits.

The 'Smart Grid, Smart City' (SGSC) project [4] undertaken between 2012 and 2014, was commissioned by so the Australian Government to trial a wide range of smart grid technologies, becoming one of the largest trials to have been conducted in the world to date [4]. From a national cost-benefit perspective, the SGSC project and other independent research conducted by the Grat- 
55 tan Institute [5] in 2015, found a real and immediate business case for the introduction of dynamic tariffs focusing on temporal energy demand in order to remove the cross-subsidies existing between non-PV owners and PV owners. Under such an environment, the uptake of small-scale PV in Australia was projected to exhibit continued growth. However in response to the recommended tariff restructures, a reduction in average size of new residential systems was forecasted to occur [4].

The removal of government incentive schemes and the 115 65 introduction of dynamic tariffs will increase the complexity of the business case for small-scale rooftop PV systems. The findings of the SGSC project and the Grattan Institute highlight the need for a comprehensive assessment tool to inform prospective investors and establish the economic efficiency of new PV systems.

An optimization strategy for residential PV systems is developed in this research. The maximization of the net benefit achieved through reduced imported energy costs is set as the underlying objective. Within a competitive 75 retail electricity market with various tariff structures including flat and dynamic time-of-use (TOU) rates, the best plan is not self-evident. The research presented in this article is principally focused towards leveraging temporal energy consumption data facilitated by smart 80 meters to develop a customer specific evaluation based on other influential factors such as location, prevailing solar insolation and available retail electricity plans. The traditional PV installation objective to maximize gross energy generation is challenged and demonstrated to be 85 not necessarily the most cost effective approach. The ultimate objective of this research is to remove the uncertainty in system specification and retail electricity plan selection in a competitive retail market and dynamic regulatory environment.

As a basis for the optimization problem defined in this article, solar insolation and PV array models are defined. Particle swarm optimization (PSO) is used as the underlying optimization algorithm, given its speed and simplicity of application to non-linear problems. The 95 standard canonical algorithm is modified first through the introduction of a penalty function and then through the introduction of a hypercube nearest vertex approach previously established in literature to enable the handling of constraints.

Actual solar insolation data from selected Australian locations, smart meter data from the SGSC project and electricity plans from three large Australian retailers are applied to the optimization problem to demonstrate the potential investment value of optimally selected PV sys- 155 tems. Although the assessment presented in this article was undertaken in an Australian context, the principles and analysis methodology are applicable to any location or country.

\subsection{Literature Review}

The optimization of PV systems have been extensively researched in literature [6, 7]. A variety of optimization methodologies were found to have been utilized including numerical methods [8, 9] and metaheuristic methods such as genetic algorithms [10-14] and PSO [15--20]. In recent times, research has focused heavily towards hybrid renewable energy systems and microgrids [11, 12, 14, 20, 21]. However given hybrid systems predominantly find applications in medium to a large scale energy systems, the objectives, assumptions and methodology are not well-suited to small-scale residential systems. Consequently limited research was found relating to the economic optimization of residential PV applications however a brief overview of existing literature is presented in this section.

Self-consumption and load matching of PV to residential loads have been investigated in [9, 10, 22]. Widen et al. [9] assessed load matching of PV combined with demand side management and energy storage systems through consideration of customer load profiles. However it was acknowledged no consideration was given to economic performance or optimal sizing of PV systems. Beck et al. [10] investigated the temporal resolution of smart meter load data on the self-consumption rate of PV generated electricity, developing an economic model to optimize the system size. However a single standardized profile from an example PV system was applied to all analyzed cases, thereby eliminating tilt and azimuth optimization from the analysis.

The economic evaluation of PV systems has been extensively investigated. Many articles consider costbenefit relationships through variations on a net present value (NPV) analysis [7, 8, 10, 12, 13, 23,-27]. Mulder et al. [23] investigated the dimensioning of PV-battery systems based on selling price and incentive conditions by utilizing smart meter data from 65 Belgian households. Although smart meter data with a relatively high resolution (15 minutes) was used in the analysis, the temporal resolution was not leveraged; rather only cumulative annual generation and consumption profiles were considered.

Pillai et al. [25] investigated the near-term economic benefits of PV systems in the UK and India by determining the prosumer energy unit cost, equivalent to levelized cost of electricity (LCOE). However the analysis was based on a national average PV system size and monthly energy demand profile rather than the circumstances of an individual customer. 
Despite the prevalence of existing literature focusing 205 on PV system optimization, no research has aimed to velop an encompassing tool at the consumer level to inform prospective residential PV owners through an integrated approach determining system size, orientation and the associated least cost retail electricity plan. 210 With the integration of smart grid technologies, particuarly the continued installation of smart meters and the introduction of dynamic electricity tariffs, such an optimization tool is required to empower customers and provide confidence in the potential investment value of 215 residential PV systems.

A similar, although more limited, assessment has been previously investigated by the authors in [28]. While the previous analysis in [28] was limited to a sample of three locations, the assessment in this article extends to a much larger sample of residences in multiple cities. ${ }^{220}$ Furthermore PV module degradation and maintenance costs were excluded from the analysis in [28]. In this article, these short comings are addressed and a more detailed definition of optimization problem is presented.

\section{Methodology}

\subsection{Solar Insolation Model}

High accuracy ground-based solar insolation data with hour (or even sub-hour) resolutions are available for only a limited number of locations. For arbitrary locations, on- ${ }^{230}$ line databases such as SolarGIS [29] and meteorological software such as Meteonorm [30] enable the generation of insolation data for any location on Earth. However access to these databases is relatively expensive from a residential PV perspective. In countries such as Australia, ${ }^{235}$ where only a relatively small number of ground-based stations have been established, only satellite-derived data are viable for most locations. The Australian Government Bureau of Meteorology provides public and free access to the 'Climate Data Online' database (CDO) [31], containing daily satellite insolation measurements 240 for thousands of Australian locations. However in order to enable PV array optimization based on hourly energy consumption data, estimations of hourly insolation from the daily satellite data are required.

Daily insolation on a horizontal plane is divided into two primary components: beam insolation $H_{b}$ (also known as direct insolation) and diffuse insolation $H_{d}$. Combined together, the two components form the global (or total) insolation $H$ as defined in Eq. (1).

$$
H=H_{b}+H_{d}
$$

Prior to calculating hourly insolation based on daily data, the daily global insolation must first be separated into its beam and diffuse components. The correlation model developed by Erbs et al. (which the reader is referred to [32] and [33]) estimates the fraction of daily diffuse insolation $H_{d}$ against daily global insolation $H$. Based on this fraction, the daily beam insolation $H_{b}$, is then easily determined through substitution of the Erbs et al. correlation into Eq. (1).

An estimate of the ratio of the hourly global insolation $I$, to the daily global insolation $H$ can be made using the model developed by Collares-Pereira and Rabl [34] as described by Eq. (2). Using a similar model defined by Liu and Jordan [35], the hourly diffuse insolation $I_{d}$, can also be estimated by Eq. (3).

$$
\begin{gathered}
\frac{I}{H}=\frac{\pi}{24}(a+b \cos \omega) \frac{\cos \omega-\cos \omega_{s}}{\sin \omega-\frac{\pi \omega_{s}}{180} \cos \omega_{s}} \\
\frac{I_{d}}{H_{d}}=\frac{\pi}{24} \frac{\cos \omega-\cos \omega_{s}}{\sin \omega-\frac{\pi \omega_{s}}{180} \cos \omega_{s}}
\end{gathered}
$$

Here $a$ and $b$ are empirically derived coefficients, $\omega$ is the solar hour angle and $\omega_{s}$ is the sunset hour angle.

Following the evaluation of Eqs. (2) and (3), the beam hourly insolation $I_{d}$, is then estimated by an equivalent hourly version of Eq. (1).

Following the establishment of estimates for horizontal insolation, a transposition model is required to transpose the horizontal insolation to the plane of tilt of the PV array. A multitude of transposition models have been developed. An evaluation of twelve models was undertaken by Noorian et al. [36] where in general the Reindl et al. [37] model, also referred to as the Hay-DaviesKlucher-Reindl (HDKR) model [33], was found to be amongst the most accurate for the locations assessed as is therefore selected for this research. The HDKR model is defined as follows:

$$
\begin{aligned}
I_{T}= & \left(I_{b}+A_{i} I_{d}\right) R_{b} \\
& +I_{d}\left(1-A_{i}\right)\left(\frac{1+\cos \beta}{2}\right)\left[1+f \sin ^{3}\left(\frac{\beta}{2}\right)\right] \\
& +I \rho_{g}\left(\frac{1-\cos \beta}{2}\right)
\end{aligned}
$$

where $I_{T}$ is the total hourly insolation on a tilted plane, $A_{i}=I_{b} / I_{o}, f=\sqrt{\left(I_{b} / I\right)}, I_{o}$ is the hourly extra-terrestrial insolation, $\rho_{g}$ is the composite 'ground' reflectance factor (assumed to be 0.2 in this research) and $R_{b}$ is the ratio of beam irradiance in the tilted plane versus the horizontal defined as:

$$
R_{b}=\frac{\cos \theta}{\cos \theta_{z}}
$$


where,

$$
\begin{aligned}
\cos \theta= & \sin \delta \sin \phi \cos \beta+\sin \delta \cos \phi \sin \beta \cos \gamma \\
& +\cos \delta \cos \phi \cos \beta \cos \omega \\
& -\cos \delta \sin \phi \sin \beta \cos \gamma \cos \omega \\
& +\cos \delta \sin \beta \sin \gamma \sin \omega
\end{aligned}
$$

$$
\cos \theta_{z}=\cos \phi \cos \delta \cos \omega+\sin \phi \sin \delta
$$

Here parameters $\theta, \theta_{z}, \beta, \gamma, \delta$ and $\phi$ refer to insolation anle of incidence, zenith angle of the sun, surface tilt, surface azimuth, solar declination angle and latitude 300 respectively [33]. It should be noted that Eq. (6) has been developed for locations in the southern hemisphere whereby $\gamma=0$ implies a surface facing due north.

Eq. (4) forms the underlying input to the PV energy yield model presented in the next section.

\subsection{Photovoltaic Energy Yield Model}

The PV energy yield model considered in this research is based on the model defined by Duffie and Beckman [33]. Using data provided on the manufacturer datasheet under nominal operating cell temperature (NOCT) and standard test conditions (STC), the operating temperature of a particular PV module can be determined through Eq. [8]:

$$
T_{c}=T_{a}+\left(T_{N O C T}-20\right) \cdot \frac{G_{T}}{800} \cdot\left(1-\eta_{m p p, s t c}\right)
$$

where $T_{a}$ is the ambient temperature, $T_{N O C T}$ is the nominal operating cell temperature, $G_{T}$ is the incident solar irradiance (i.e. power per unit area) and $\eta_{m p p, s t c}$ is the maximum power point efficiency at standard test conditions.

The operating efficiency of the PV module at particular environmental conditions is defined as:

$$
\eta_{m p p}=\eta_{m p p, s t c}+\mu_{m p p}\left(T_{c}-T_{a}\right)
$$

where $\mu_{m p p}\left(\% /{ }^{\circ} \mathrm{C}\right)$ is the power-temperature coefficient provided on the module datasheet.

According to [33], the output power of a PV array at any particular instant, assuming the array has maximum power point tracking, can be described by:

$$
P_{p v}=A_{c} Z G_{T} \eta_{m p p} \eta_{e} D_{y}
$$

where $A_{c}$ is the PV module area, $Z$ is the number of PV modules, $\eta_{e}$ is the efficiency of associated balance of plant (including the maximum power point tracking inverter and other loss associated equipment) and $D_{y}$ is the PV module degradation factor in year $y$. performance warranty whereby the module output degrades linearly over the warranty period. Consequently the degradation factor $D_{y}$ can be expressed as follows:

$$
D_{y}=D_{1}-r_{d e g}(y-1) \quad \text { for } 1 \leq y \leq Y
$$

where $r_{d e g}$ is the manufacturer prescribed degradation rate and $D_{1}$ is the degradation factor in the first year (since performance equal to $100 \%$ of the rated output is not usually guaranteed).

If the instantaneous power is integrated over time and $G_{T}$ is assumed to be constant over the period so that the hourly isolation $I_{T}=G_{T}$, then the energy produced by the PV array over an hour is defined as:

$$
E_{p v}=A_{c} Z I_{T} \eta_{m p p} \eta_{e} D_{y}
$$

Eq. (12) constitutes the underlying energy yield model lem define in Section 2.4 .

\subsection{Economic Model}

Due to the relatively long lifetime of PV systems, the time value of money must be considered. The option to invest in a PV system must be compared against other investment options that are realistically expected to earn a minimum rate of return. The time value of money is most commonly considered through a present value analysis. For a given investment option, future cash flows are discounted to yield their present value. Summation of the present value of each cash flow and subtracting the initial cost of the investment yields the NPV of the investment. NPV is therefore expressed as:

$$
N P V=\sum_{q=1}^{Q} \frac{C_{q}}{\left(1+r_{n o m}\right)^{q}}-C_{0}
$$

where $C_{0}$ is the initial investment cost, $C_{q}$ is the cash flow in period $q, Q$ is the number of billing periods and $r_{\text {nom }}$ is the nominal discount rate. The discount rate is defined as the opportunity cost of capital - the return an investor reasonably expects to yield from welldefined alternative investment options. For the analysis presented in this paper, the cost of capital is assumed to be $6 \%$ p.a., chosen to be reflective of standard investment options available to a typical home owner.

In addition to the time value of money, the purchasing sо power of the currency, which diminishes due to inflation, must also be considered. Inflation can be included in the economic model by modifying the nominal discount rate to yield a real discount rate defined by Eq. (14):

$$
r_{\text {real }}=\frac{\left(1+r_{\text {nom }}\right)}{\left(1+r_{\text {inf }}\right)}-1
$$


where $r_{\text {real }}$ and $r_{\text {inf }}$ are the real discount and inflation rates. Assuming the more conservative inflation rate of $2 \%$ within the Reserve bank of Australia's target range of $2-3 \%$ [38], the real discount rate considered in this research is $3.92 \%$.

For retail electricity, typical billing periods are monthly or quarterly. Therefore the assumed annual rates must be converted to an effective rate based on the period of billing as given by Eq. (15):

$$
r_{e f f}=\left(1+r_{\text {real }}\right)^{1 / t}-1
$$

where $r_{e f f}$ is the effective real rate for the period and $t$ is the number of billing periods per year. For quarterly billing $(t=4)$, the effective quarterly rate, assuming $r_{\text {real }}=3.92 \%$, is $r_{\text {eff }}=0.97 \%$.

Although NPV analysis is predominantly the primary metric for assessing investment options, the rate of return is also critically important to establish investment preferences among competing options. For the economic analysis considered in this paper, the modified internal rate of return (MIRR) [39] as defined in Eq. [16] is used:

$$
M I R R=\sqrt[Q]{\frac{\sum_{q=1}^{Q} C_{q}^{+}\left(1+r_{i n v}\right)^{(Q-q)}}{C_{0}+\sum_{q=1}^{Q} C_{q}^{-}\left(1+r_{f i n}\right)^{-q}}}-1
$$

where $r_{i n v}$ and $r_{f i n}$ are the re-investment and finance 405 rates respectively (both assumed to be equivalent to $r_{\text {eff }}$ ), while $C_{q}^{+}$and $C_{q}^{-}$denote positive and negative cash flows ative cash flows are associated with maintenance and equipment replacement costs in the context of a PV sys- 410 tem.

In this article, MIRR is not directly incorporated into the optimization problem problem but used as a separate metric after NPV is optimized. Ideally, the MIRR should be greater than the cost of capital. In this article, an in- 415 vestment yielding such a return is defined as a 'viable' investment. However despite the 'viable' investment tems complicates the decision criteria - an investor may consider an MIRR slightly lower than the cost of capital to be acceptable in order to reduce their net carbon emissions. Thus, in the context of residential PV systems, requirement for an MIRR greater than the cost of capital should not be seen as prescriptive, but used rather as a supporting metric for NPV to be balanced with an investor's desire to reduce their environmental footprint. payback period defined as:

$$
P=A+\frac{B}{C}
$$

where $P$ is the payback period, $A$ is the number of periods whereby the cumulative cash flow is negative, $B$ is the residual cost to be paid back in period $A+1$ and $C$ is the total cash flow in period $A+1$. A PV system may yield both a positive NPV and adequate MIRR over its design life, however if a particular investor intends to relocate before the expiration of the system life (thus prior to the realization of any net benefit), knowledge of the payback period is crucial.

\subsection{Optimization Problem}

The optimization objective is to maximize the monetary savings achieved by installing an optimally sized and oriented PV system. The savings, defined as the difference between the cost of electricity with an optimized PV system under a given retail electricity plan, against a known lowest cost 'do nothing' plan, are quantified through the NPV analysis defined in Section 2.3 400 Through a comparison of the optimized systems for each of the retail electricity plans available to an individual customer, the optimal system and tariff structure for a particular residence can be determined.

The defining equations for the optimization problem and the subsequent analysis in this research are based in an Australian context. Insolation and energy consumption data for a sample of Australian customers are used. Furthermore the economic parameters, system costs and available incentive schemes are reflective of the Australian PV industry. However the problem is easily transferable to other national contexts given equivalent economic parameters, tariff structures and system costs.

The optimization problem considered in this article is defined as follows:

Given:

(1) Latitude

(2) Hourly energy consumption and solar insolation

(3) Maximum number of PV modules $\left(Z_{\max }=30\right)$

(4) PV cost per watt peak $\left(U_{p v}=\$ 2.37 / \mathrm{W}_{\mathrm{p}}\right)$ [40]

(5) Inverter replacement cost $\left(U_{i n v}=\$ 0.35 / \mathrm{W}_{\mathrm{p}}\right)$ [40]

(6) Billing frequency (quarterly)

(7) Effective real discount rate $r_{\text {eff }}=0.97 \%$

(i.e. $r_{\text {nom }}=6 \%$ and $r_{\text {inf }}=2 \%$ )

(8) PV system balance of plant efficiency $\eta_{e}=90 \%$

(9) System lifespan (20 years) 
Find: Tilt angle $\beta$, azimuth angle $\gamma$, and number of modules $Z$

\section{Objective:}

$$
\begin{aligned}
\max _{\beta, \gamma, Z} N P V=\sum_{q=1}^{Q} & {\left[\frac{\left(C_{\text {base }, q}-C_{p v, q}(\beta, \gamma, Z)\right)\left(1+r_{g}\right)^{q}}{\left(1+r_{e f f}\right)^{q}}\right.} \\
& \left.-\frac{M_{q}(Z)}{\left(1+r_{e f f}\right)^{q}}\right]-S_{p v}(Z)
\end{aligned}
$$

Subject to:

$$
\begin{aligned}
& 0 \leq \beta \leq 180^{\circ}, \text { for } \beta \in \mathbb{R} \\
&-180^{\circ} \leq \gamma \leq 180^{\circ}, \text { for } \gamma \in \mathbb{R} \\
& 0 \leq Z \leq Z_{\max }, \text { for } Z \in \mathbb{Z}^{+}
\end{aligned}
$$

In Eq. (18), $C_{p v, q}$ and $C_{b a s e, q}$ refer to the cost of electricity with and without a PV system respectively within the billing period $q$ (the difference of which constitutes the monetary savings achieved through the installation of PV). $S_{p v}$ is the PV system cost, $Q$ is the number of billing periods over the lifetime of the system and $M_{q}$ is the maintenance cost in period $q$. Expressions for $C_{\text {base }, q}$, 485 $C_{p v, q}, M_{q}$ and $S_{p v}$ are defined in Eq. 20p-24).

Eq. (18) includes an additional growth factor $\left(1+r_{g}\right)^{q}$ to allow for retail electricity price growth above (or below) the rate of inflation. In an Australian context since 1990 , electricity price rises have significantly outpaced inflation on average by $2-3 \%$ per annum in real terms [41]. Consequently, electricity price growth is assumed to be $2 \%$ in real terms, becoming $r_{g}=0.05 \%$ when 490 converted to an effective quarterly rate for the quarterly billing assumed in this research.

$$
C_{\text {base }, q}=\sum_{d=1}^{D_{q}}\left[\sum_{h=1}^{24}\left(T_{\text {grid } 0, q d h} E_{\text {load }, q d h}\right)+T_{s c 0, q d}\right]
$$

$$
\begin{aligned}
& C_{p v, q}(\beta, \gamma, Z)= \\
& \sum_{d=1}^{D_{q}}\left\{\sum _ { h = 1 } ^ { H } \left[T_{g r i d, q d h} \max \left(0, E_{b a l, q d h}(\beta, \gamma, Z)\right)\right.\right.
\end{aligned}
$$

$\left.\left.-T_{f e e d, q d h} \max \left(0,-E_{b a l, q d h}(\beta, \gamma, Z)\right)\right]+T_{s c, q d}\right\}$

$$
E_{b a l, q d h}(\beta, \gamma, Z)=E_{l o a d, q d h}-E_{p v, q d h}(\beta, \gamma, Z)
$$

In Eqs. 20) and (21), for hour $h$ of day $d$ in billing period $q$ (with $D_{q}$ days in the billing period), $T_{\text {grid } 0, q d h}$ and $T_{\text {grid,qdh }}$ represent the tariffs associated with grid imported electricity under a base plan (i.e. lowest cost 'do nothing' plan) and a tested plan respectively; $E_{b a l, q d h}$ is the balance of net energy flow defined in Eq. (22) as the difference between load energy $E_{\text {load,qdh }}$ and the PV generated energy $E_{p v, q d h}$; and $T_{f e e d, q d h}$ is the PV FiT. $T_{s c 0, q d}$ and $T_{s c, q d}$ are the daily electricity supply charges for the base plan and tested plan respectively.

The total PV system cost $S_{p v}$ for a system of rated power $P_{p v, r a t}$, defined in Eq. 23, can be reduced through government initiated rebates and incentive schemes. In an Australian context, the total sytem cost to the investor is reduced through an effective rebate provided under the SRES. Under this scheme, small-scale technology certificates are generated and traded on an open market as a commodity to be ultimately purchased by liable entities (usually energy retailers) [3]. The quantity of certificates generated depends on the size, location and length of time the system is expected to contribute to the SRES. In 2016, certificates were generated for up to 15 years yielding a contribution lifetime of $M_{\text {life }}=15$ [42]. The location multiplier is assumed to be $M_{l o c}=1.382$ for the locations assessed in this paper [42]. In this paper, the PV investor is assumed to receive $C_{c e r t}=\$ 32$ for each certificate.

$$
S_{p v}(Z)=U_{p v} P_{p v, r a t}(Z)-M_{l i f e} M_{l o c} P_{p v, r a t}(Z) C_{c e r t}
$$

The objective function of Eq. 18) considers the cost of maintenance $M_{q}$ in the NPV analysis. Although small-scale residential systems are largely maintenance free, periodic system inspections are required. Definitive guidelines for maintenance frequency and statistical costs have not been universally established. Consequently, in this article maintenance is assumed to be carried out every five years at a cost of $\$ 200$, a reasonably 495 assumption provided the system is properly installed. Furthermore, while PV modules are known to have relatively long operational lifespans (in excess of 20 years), inverters usually require replacement at least once over the lifetime of the system. In this research, inverter replacement has been assumed to occur after ten years of operation. Consequently, based on the assumptions above and recognising that $t$ is the number of billing periods per year, maintenance is therefore required every $5 t$ (maintenance only) and $10 t$ billing periods (mainte(me maintenance costs defined by Eq. 24) are determined at the start of each billing period, where $U_{\text {inv }}$ refers to the inverter replacement cost per watt peak $\left(\$ / \mathrm{W}_{\mathrm{p}}\right)$. If maintenance is due, $M_{q}$ defined by Eq. (24) forms a negative cash flow in 
Eq. (18) for period $q$.

$$
M_{q}(Z)= \begin{cases}200 & \text { if } \frac{q-1}{5 t} \in \mathbb{Z}^{+}, \frac{q-1}{10 t} \notin \mathbb{Z}^{+} \\ 200+U_{i n v} S_{p v}(Z) & \text { if } \frac{q-1}{10 t} \in \mathbb{Z}^{+} \\ 0 & \text { otherwise }\end{cases}
$$

\subsection{Optimization Algorithm}

PSO has seen many applications in PV optimization problems due to the complex non-linear equations involved and its excellent performance under such conditions [6]. For this research, PSO is selected due to its speed, global search performance and relative simplicity 565 of application [43].

${ }_{520}$ Originally developed by Kennedy and Eberhart [44], PSO simulates the social interaction within bird flocks and fish schools to achieve a global objective in the absence of centralized control [43]. Each swarm agent ${ }_{57}$ is represented as a particle with infinitesimal volume position and velocity vectors, where $J$ is equivalent to the number of optimization parameters in the problem (i.e. $J=3$ in this research). Consequently for the $i^{\text {th }}$ particle in the $n^{\text {th }}$ iteration, the position and velocity ${ }_{530}$ vectors $\boldsymbol{x}_{i, n}$ and $\boldsymbol{v}_{i, n}$ are respectively defined as:

$$
\begin{gathered}
\boldsymbol{x}_{i, n}=\left(x_{i, n}^{1}, x_{i, n}^{2}, x_{i, n}^{3}\right)=\left(\beta_{i, n}, \gamma_{i, n}, Z_{i, n}\right) \\
\boldsymbol{v}_{i, n}=\left(v_{i, n}^{1}, v_{i, n}^{2}, v_{i, n}^{3}\right)
\end{gathered}
$$

In iteration $n+1$, updates of the dimensional compo- ${ }_{580}$ nents of position $\left(x_{i, n}^{j}\right)$ and velocity $\left(v_{i, n}^{j}\right)$ for each particle are performed through knowledge of the global best position within the swarm and the personal best position for each particle. The component-wise updates for each particle are defined by Eq. 27) and Eq. 28):

$$
\begin{gathered}
v_{i, n+1}^{j}=\chi \\
\chi v_{i, n}^{j}+c_{1} r_{i, n}^{j}\left(P_{i, n}^{j}-x_{i, n}^{j}\right) \\
\left.+c_{2} R_{i, n}^{j}\left(G_{i, n}^{j}-x_{i, n}^{j}\right)\right] \\
x_{i, n+1}^{j}=x_{i, n}^{j}+v_{i, n+1}^{j}
\end{gathered}
$$

${ }_{545}$ where, $c_{1}$ and $c_{2}$ are acceleration coefficients, $r_{i, n}^{j}$ and $R_{i, n}^{j}$ are two sequences of uniformly distributed random numbers over $(0,1), P_{i, n}^{j}$ is the personal best position and $G_{i, n}^{j}$ is the global best position of the swarm, for particle $i$ in dimension $j$. A modification of the original PSO algorithm is performed through the inclusion of a constriction factor term $\chi$ which gives significantly improved con- 595 vergence performance [43]. Eq. [27] is consequently termed PSO with constriction factor (PSO-Co), one of the two basic algorithms defined as canonical PSO [43]. ${ }_{55}$ In this research, $c_{1}, c_{2}$ and $\chi$ were set according to the recommendations of [43], defined to be 2.05, 2.05 and 0.729 respectively.

The algorithm continues until the termination conditions are met, i.e. the global best position is found (to an accepted level of accuracy) or the maximum number of iterations $N$ has been reached, as defined by the user.

A flow chart of the PSO optimization algorithm applied to the optimization problem defined in Section 2.4 is presented in Fig. 11. The standard PSO processes are represented as colorless cells. To differentiate the standard PSO procedures from the unique application explored in this article, the optimization problem and underlying models defined in Sections 2.1 2.4 are represented by the blue cells.

A common method to handle optimization constraints is to introduce a penalty function into the objective function [45] so that the revised objective function takes the form:

$$
F(\boldsymbol{x})=f(\boldsymbol{x})+H(\boldsymbol{x}, n)
$$

where $f(\boldsymbol{x})$ is the original objective function defined by Eq. $(18)$ and $H(x, n)$ is the penalty function. In this research, in order to manage the size and orientation constraints of a PV system, $H(x, n)$ takes the form defined by Parsopoulos and Vrahatis [46] and further explored by Sun et al. [45]:

$$
H(\boldsymbol{x}, n)=h(n) \sum_{k=1}^{K} \psi\left(\lambda_{k}(\boldsymbol{x})\right) \lambda_{k}(\boldsymbol{x})^{\alpha\left(\lambda_{k}(\boldsymbol{x})\right)}
$$

The terms in Eq. 30 include a relative violated function of the constraints $\lambda_{k}(\cdot)$ (so that the penalty function is zero when all optimization parameters are within their associated constraints); a multi-stage assignment function $\psi(\cdot)$ (which scales the penalty depending on the value of $\lambda_{k}(\cdot)$; a power function $\alpha(\cdot)$; and a dynamically modified penalty value $h(n)$ based on the iteration number. In Eq. (30), $K$ refers to the number of constraints in the optimization problem and subsequently for the problem defined in Section 2.4 $K=3$.

The penalty parameters of Eq. (30) are problem dependent [46]. In this research, the values considered by Parsopoulos and Vrahatis in [46] were used with a few minor modifications to improve convergence performance. The penalty parameters used in this research are 


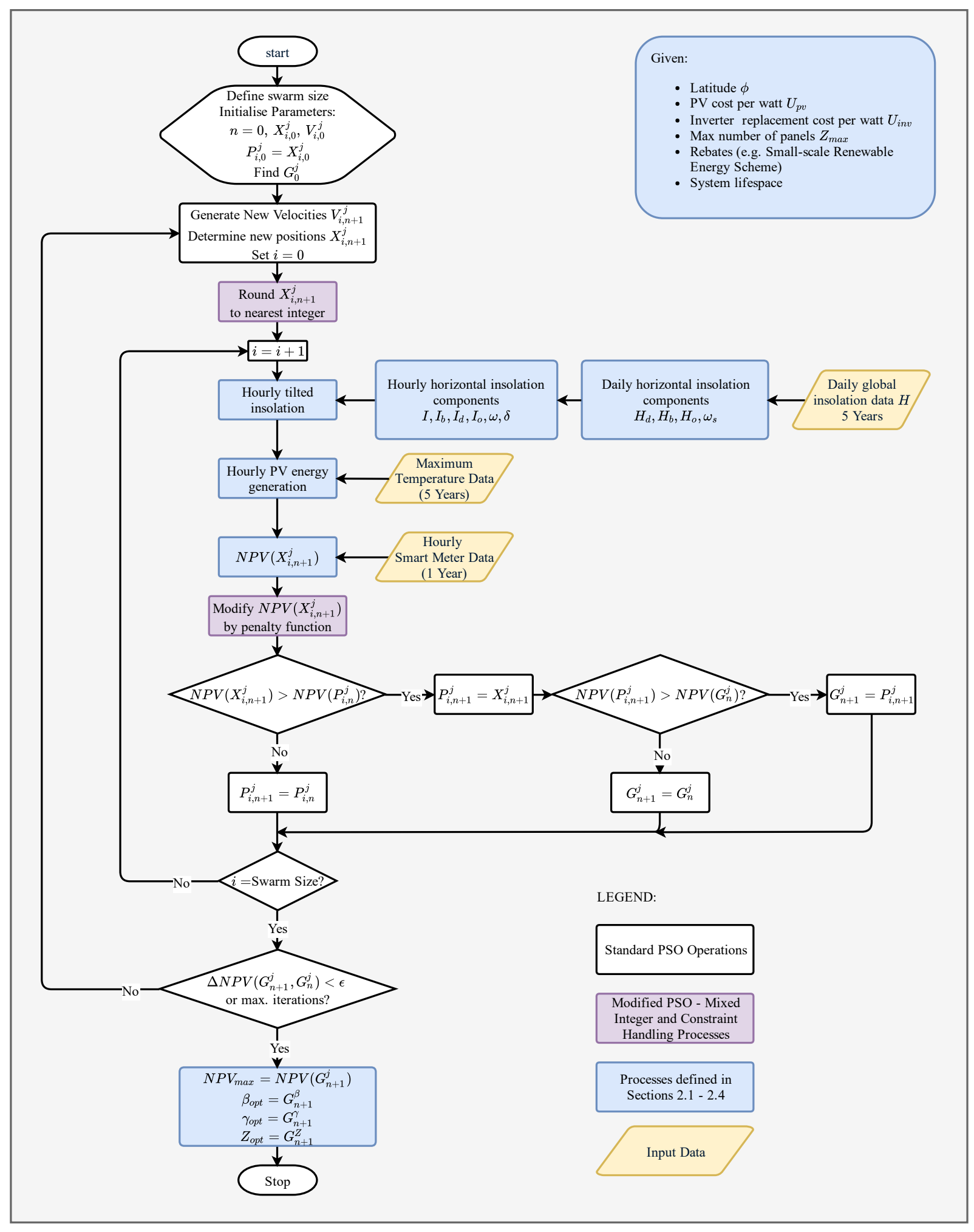

Fig. 1. Flow chart of optimization problem. 
subsequently defined in Eq. 31a-31d:

$$
\begin{aligned}
h(n) & =n \sqrt{n} \\
\lambda_{k}(\boldsymbol{x}) & =\max \left(0, g_{k}(\boldsymbol{x})\right) \\
\alpha\left(\lambda_{k}(\boldsymbol{x})\right) & = \begin{cases}1 & \text { for } \lambda_{k}(\boldsymbol{x})<1 \\
2 & \text { otherwise }\end{cases} \\
\psi\left(\lambda_{k}(\boldsymbol{x})\right) & = \begin{cases}10 \text { for } \lambda_{k}(\boldsymbol{x}) \leq 0.01 \\
20 \text { for } 0.01<\lambda_{k}(\boldsymbol{x}) \leq 0.1 \\
100 \text { for } 0.1<\lambda_{k}(\boldsymbol{x}) \leq 1 \\
300 \text { otherwise }\end{cases}
\end{aligned}
$$

where $g_{k}(\boldsymbol{x})$ are the constraint functions of the defined optimization problem reformulated in the form

$g_{k}(\boldsymbol{x}) \leq 0$. The constraints of Eq. (19) re-written in the 65 form $g_{k}(\boldsymbol{x}) \leq 0$ therefore become:

$$
\begin{aligned}
& g_{1}(\boldsymbol{x})=|\beta-90|-90 \leq 0 \text { for } \beta \in \mathbb{R} \\
& g_{2}(\boldsymbol{x})=|\gamma|-180 \leq 0 \text { for } \gamma \in \mathbb{R} \\
& g_{3}(\boldsymbol{x})=\left|Z-\frac{Z_{\text {max }}}{2}\right|-\frac{Z_{\text {max }}}{2} \leq 0 \text { for } Z \in \mathbb{Z}^{+}
\end{aligned}
$$

Referring to Eq. 32a-32c), it should be noted that the optimization variable $Z$ is limited to integer values while $\beta$ and $\gamma$ may take any real value within the domain of the constraints. Consequently the optimization problem may be classified as a mixed-integer non-linear 665 programming problem.

In order to handle the integer constraints, the method adopted by Chowdhury et al. [47] was utilized whereby the continuous and discrete components of the particles are first separated. The locations of the discrete compo- 670 nents are approximated by the nearest vertex of a local of hypercube in $J$-dimensional space [47]. More simply, the particle's discrete components are approximated in each dimension by rounding to the nearest integer value. All components, both continuous and discrete, are then ${ }^{67}$ evaluated according to Eqs. (27) and (28).

The constrained mixed-integer modifications to the standard canonical PSO algorithm are identified as purple cells in the flow chart of Fig. 1. It should be noted that although tilt $\beta$ and azimuth $\gamma$ are not restricted to integer values, such accuracy is difficult to achieve and unnecessary given the insignificant energy gains achievable. Consequently, the nearest vertex approach was also applied for the tilt and azimuth parameters in the subsequent analysis.

The PSO algorithm was developed and simulated in Matlab version R2015b.

\subsection{Input Data}

Between 2012 and 2014, the SGSC project collected 690 dences in the state of New South Wales, Australia [4]. In 2015, the data was made publicly available by the Australian Government Department of Industry, Innovation and Science [48], presenting an ideal data source to in645 vestigate the optimization of residential PV installations.

Given the extensive time required to process the large amount of customer data available, a sample of customers was randomly selected to test the optimization strategy developed in Section 2.4. The sample included four residences from both rural and urban regions and a larger focus group of 120 residences from the city of Newcastle. The sample of Newcastle residence was divided into three relative energy consumption categories with 40 members each, based on the 3-quantiles of the distribution of yearly energy consumption $E_{\text {year }}$. For the sample of residences selected, the categories were defined as:

$$
\begin{array}{lr}
\text { Low: } & E_{\text {year }} \leq 3,590.5(\mathrm{kWh} / \text { year }) \\
\text { Medium: } & 3,590.5<E_{\text {year }} \leq 6,122.6(\mathrm{kWh} / \text { year }) \\
\text { High: } & E_{\text {year }}>6,122.6(\mathrm{kWh} / \text { year })
\end{array}
$$

Satellite-derived daily global horizontal insolation data from the nearest Australian Bureau of Meteorology weather stations were utilized in the analysis, accessed from the CDO database [31]. To reduce the likelihood of under or over estimation of insolation due to anomalous meteorological years, data from five consecutive years between 2011 and 2015 were utilized. Using Eq. (1)-(3), the daily data were processed to derive estimated hourly insolation components.

Hourly ambient temperature data were not available for the assessed weather station locations. Consequently, the ambient temperatures for PV array operation were assumed to be the measured daily maximum temperature for all hours of operation, yielding conservative estimates for PV performance. Temperature data for the same five year period as the insolation data were also accessed from the CDO database [31].

The energy tariffs used in this research are based on the available standing offers in September 2016 from three of the largest energy retailers in Australia. The four customers considered the initial analysis were located within the same distribution network jurisdiction as Newcastle. Consequently the available retail plans for these customers were assumed to be equivalent to those of Newcastle. For each retailer, a flat tariff and a TOU tariff were considered for which example rate profile is shown in Fig. 2 It should be noted that variable weekend TOU rates and incremental flat tariffs based on cumulative energy consumption within a given period were also considered but have been omitted in Fig. 2 
Table 1

Comparison of optimized PV systems for different retail electricity plans and different customers.

\begin{tabular}{|c|c|c|c|c|c|c|c|c|c|}
\hline Customer & Retailer & Tariff & Size $(\mathrm{kW})$ & Tilt & Azimuth & NPV & MIRR & Payback (Years) & Plan Saving \\
\hline \multirow{6}{*}{1} & A & TOU & 6.77 & $31^{\circ}$ & $21^{\circ}$ & $\$ 7,182$ & $6.01 \%$ & 12.0 & $\$ 254$ \\
\hline & A & Flat & 6.52 & $31^{\circ}$ & $2^{\circ}$ & $\$ 7,257$ & $6.10 \%$ & 11.6 & $\$ 329$ \\
\hline & B & TOU & 7.02 & $31^{\circ}$ & $21^{\circ}$ & $\$ 7,543$ & $6.03 \%$ & 12.0 & $\$ 614$ \\
\hline & B & Flat & 6.52 & $31^{\circ}$ & $1^{\circ}$ & $\$ 7,815$ & $6.24 \%$ & 11.0 & $\$ 887$ \\
\hline & $\mathrm{C}$ & TOU & 7.02 & $31^{\circ}$ & $21^{\circ}$ & $\$ 7,189$ & $5.94 \%$ & 12.3 & $\$ 260$ \\
\hline & $\mathrm{C}$ & Flat & 6.77 & $31^{\circ}$ & $2^{\circ}$ & $\$ 6,928$ & $5.94 \%$ & 12.3 & $\$ 0$ \\
\hline \multirow{6}{*}{2} & A & TOU & 6.52 & $28^{\circ}$ & $32^{\circ}$ & $\$ 8,849$ & $6.51 \%$ & 10.0 & $\$ 2,127$ \\
\hline & A & Flat & 5.26 & $25^{\circ}$ & $9^{\circ}$ & $\$ 7,258$ & $6.54 \%$ & 9.8 & $\$ 536$ \\
\hline & B & TOU & 7.02 & $28^{\circ}$ & $33^{\circ}$ & $\$ 9,427$ & $6.49 \%$ & 10.0 & $\$ 2,705$ \\
\hline & B & Flat & 5.51 & $25^{\circ}$ & $9^{\circ}$ & $\$ 7,693$ & $6.57 \%$ & 9.8 & $\$ 971$ \\
\hline & $\mathrm{C}$ & TOU & 7.02 & $28^{\circ}$ & $33^{\circ}$ & $\$ 9,008$ & $6.39 \%$ & 10.6 & $\$ 2,286$ \\
\hline & $\mathrm{C}$ & Flat & 5.26 & $26^{\circ}$ & $8^{\circ}$ & $\$ 6,722$ & $6.38 \%$ & 10.6 & $\$ 0$ \\
\hline \multirow{6}{*}{3} & A & TOU & 2.51 & $30^{\circ}$ & $29^{\circ}$ & $\$ 447$ & $4.25 \%$ & 18.5 & $\$ 0$ \\
\hline & A & Flat & 2.26 & $28^{\circ}$ & $5^{\circ}$ & $\$ 1,720$ & $5.48 \%$ & 13.7 & $\$ 1,273$ \\
\hline & B & TOU & 2.76 & $31^{\circ}$ & $30^{\circ}$ & $\$ 652$ & $4.37 \%$ & 18.0 & $\$ 205$ \\
\hline & B & Flat & 2.26 & $28^{\circ}$ & $5^{\circ}$ & $\$ 2,129$ & $5.81 \%$ & 12.9 & $\$ 1,682$ \\
\hline & $\mathrm{C}$ & TOU & 2.76 & $31^{\circ}$ & $30^{\circ}$ & $\$ 456$ & $4.21 \%$ & 18.5 & $\$ 9$ \\
\hline & $\mathrm{C}$ & Flat & 2.26 & $28^{\circ}$ & $5^{\circ}$ & $\$ 1,670$ & $5.44 \%$ & 13.7 & $\$ 1,223$ \\
\hline \multirow{6}{*}{4} & A & TOU & 3.00 & $27^{\circ}$ & $32^{\circ}$ & $\$ 3,993$ & $6.46 \%$ & 10.1 & $\$ 174$ \\
\hline & A & Flat & 2.76 & $25^{\circ}$ & $4^{\circ}$ & $\$ 3,903$ & $6.61 \%$ & 9.6 & $\$ 84$ \\
\hline & B & TOU & 3.26 & $27^{\circ}$ & $32^{\circ}$ & $\$ 4,321$ & $6.46 \%$ & 10.1 & $\$ 502$ \\
\hline & B & Flat & 2.76 & $25^{\circ}$ & $3^{\circ}$ & $\$ 4,331$ & $6.85 \%$ & 8.8 & $\$ 513$ \\
\hline & $\mathrm{C}$ & TOU & 3.26 & $27^{\circ}$ & $33^{\circ}$ & $\$ 4,127$ & $6.36 \%$ & 10.6 & $\$ 309$ \\
\hline & $\mathrm{C}$ & Flat & 2.76 & $25^{\circ}$ & $4^{\circ}$ & $\$ 3,819$ & $6.56 \%$ & 9.9 & $\$ 0$ \\
\hline
\end{tabular}

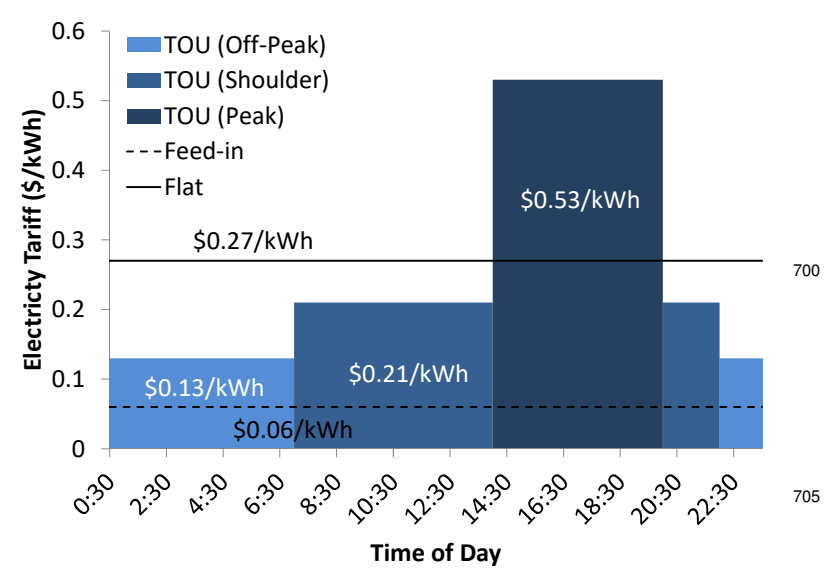

Fig. 2. Typical electricity tariff structures

for clarity. Detailed tariff tables for the retail electricity plans assumed in this article are provided in Appendix C.

The PV arrays were modelled as Trina Solar TSM250PD05.05 250 watt multicrystalline PV modules. The 715 relevant performance characteristics are detailed in $\mathrm{Ap}$ pendix B.

\section{Results and Discussion}

\subsection{Four Residences}

Table 1 summarizes the results of the optimization problem of Section 2.4 for four residences arbitrarily selected from the SGSC database. The identities of each of retailer are withheld and are designated as either Retailer A, B or C.

Referring to Table 1 , it can be seen that for all retail electricity plans, an investment in PV yielded a positive NPV. For each customer, the retail plan and associated optimized PV system giving the highest NPV are highlighted in gray.

For Customers 1, 2 and 4, at least one retail electricity plan, combined with an optimized PV system, resulted in a positive NPV and a MIRR greater than the nominal cost of capital $(6 \%)$, thus indicating a viable investment. The optimal system for Customer 3 resulted in an MIRR 
of $5.81 \%$; less than the required rate of return and thus indicating PV is a non-optimal financial investment option.

The payback periods of the optimal systems ranged ears, well within the assumed lifetime of the PV system of 20 years.

In Table 1, the PV systems are generally oriented towards the west, with TOU and having a marginal increase in tilt angle compared with flat plans. For the customers assessed, periods of peak electricity demand occurred in the afternoon/evening. Consequently, the orientation of the optimized PV systems were biased towards afternoon solar hours. While this is easily rationalized for TOU plans, for flat tariffs one would inisouth for northern hemisphere), towards the midday sun and the solar energetic maximum. However due to the comparatively low feed-in tariffs offered by the retailers assessed, the azimuths of the PV systems under flat plans are also slightly biased towards the afternoon peak in order to reduce the cost of grid-imported electricity and the comparatively high cost attached to it.

The final column of Table 1 summarizes the comparative savings that can be achieved through the correct hoice of retail electricity plan. Referring to Customer 2 and comparing the highest NPV solution (Retailer B, TOU) with the worst solution (Retailer C, flat), an increase in NPV of $\$ 2,705$ can be achieved. This figure represents a substantial saving, demonstrating the necessity to choose the most cost effective plan for a customer's particular circumstances.

The sensitivity of NPV to system size was assessed for Customer 3 and graphically presented in Fig. 3. The peak of each curve corresponds to the optimal systems recorded in Table 1, further highlighted by the dotted vertical and horizontal lines. Immediately discernible in the figures, is the significant reduction in NPV as the PV system sizes increase beyond the optimal. Even if an investor has the available capital to install a substantially sized system, the NPV of such an investment may be far less than an alternative smaller optimized system.

The sensitivity of NPV to tilt and azimuth is demonstrated by the contour plot of Fig. 4 for Customer 2. 775 While a significant impact on NPV can be observed for systems with tilts approaching the vertical and oriented facing far west or east, for orientations in the vicinity of the optimal position, NPV can be seen to be only marginally effected. Therefore it can be concluded tilt 780 and azimuth have limited contributions to the achievable NPV, provided the tilt and azimuth are within $\pm 10^{\circ}$ and $\pm 20^{\circ}$ of the optimal angles respectively.

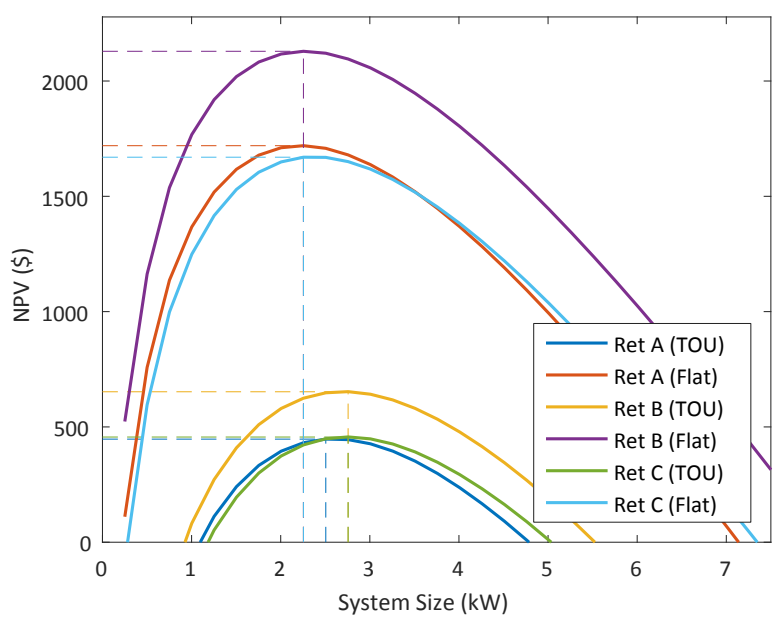

Fig. 3. NPV sensitivity to system size (Customer 3).

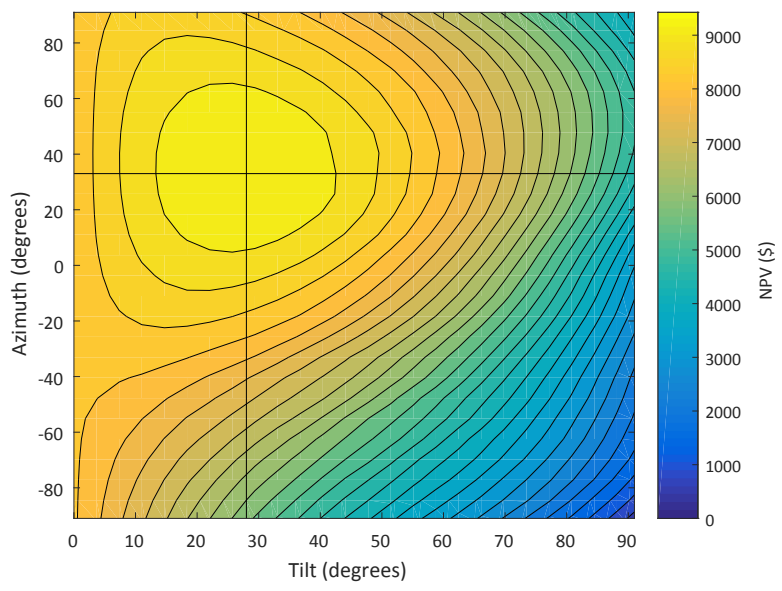

Fig. 4. NPV sensitivity to tilt and azimuth (Customer 2).

\subsection{Large Sample}

A wider sample size was considered using energy consumption data for 120 customers in the city of Newcastle, New South Wales, Australia. Using the methodology established in Section 2, PV systems were optimized for each customer.

A breakdown of the proportional contribution of each optimization parameter to the total NPV under TOU and flat plans is provided in Fig. 5. The contribution of azimuth angle is significantly larger for TOU plans than flat plans, however the contribution is still limited, with only a $5 \%$ increase in NPV achieved under TOU plans. Therefore it can be concluded that even with PV systems optimally aligned further west (or east) based on the temporal energy usage profile, only small gains in net benefit can be achieved. Due to the difficulties customizing azimuth angles on residential rooftops, the 
additional effort and cost may not be justifiable given 820 785 the limited benefit.
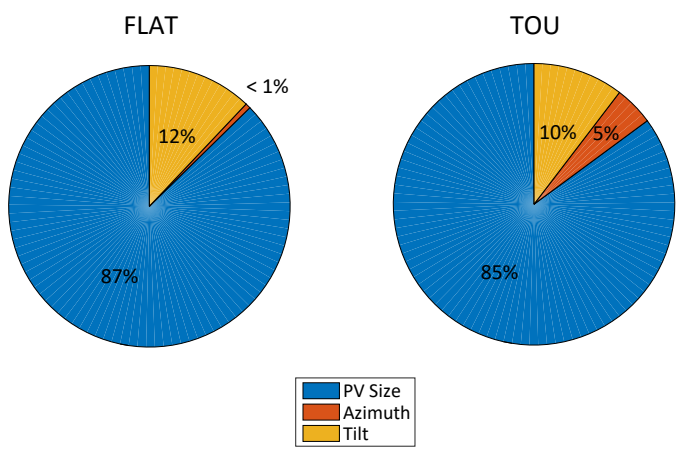

Fig. 5. Average contribution of each optimization parameters to total NPV for all Newcastle customers.

A proportional breakdown of the optimal retail plans is given in Fig. 6. The optimal plans observed included both flat and TOU plans from Retailer B and a flat plan from Retailer C. Amongst the sample of 120 customers, no retail plan from Retailer A was found to be yield the highest NPV.

It is immediately evident in Fig 6 that the flat plan from Retailer B is the best choice plan for the majority of low energy residences, with the potential to secure $88 \%$ of the market amongst the 40 selected customers. As energy consumption increases, the TOU plan from Retailer B seizes a progressively higher proportion of the market from $13 \%$ (low energy) to $45 \%$ (high energy), with a combined market percentage of $32.7 \%$ across the entire population.

Box plots showing the inter-quartile ranges of key economic performance metrics are presented in Fig. 7(a)-(e) with the sample population categorized based on relative cumulative energy consumption profile. The median and interquartile ranges for each economic parameter are further summarized in Table 2 .

Referring to Fig. 7(a) and Table 2, the median NPV and interquartile ranges amongst the sample of customers clearly increase as the energy consumption category increases. For customers with low energy usage, the median NPV for an optimized PV system was found to be $\$ 1,471$ over 20 years representing a average saving of $\$ 74$ per year in 2016 currency. In comparison, the median NPV for medium and high energy consumers were found to be $\$ 3,230$ and $\$ 6,269$, respectively representing savings of roughly $\$ 162$ and $\$ 313$ per year. It should be highlighted that these average savings represent the real achievable savings after factoring in all costs.

From a population perspective, the median PV system sizes and NPVs were found to be closely related, as demonstrated by the similar trends in the box plots of Fig. 7(a) and Fig.7(b). As summarized in Table 2, the median sizes for low, medium and high energy customers were $1.38 \mathrm{~kW}, 2.88 \mathrm{~kW}$ and $5.26 \mathrm{~kW}$ respectively. It is apparent based on the median value and the inter-quartile ranges that the size of optimized PV systems is larger for customers with higher energy consumption.

To test if the low, medium and high distributions were in fact different, hypothesis tests were undertaken on the mean of each sample via the $t$-test as detailed in Appendix A. For the null hypothesis, the means of two samples were considered to be equal (implying equivalence between the distributions); the alternative hypothesis therefore being the unequal means. A summary of the subsequent results of the hypothesis tests is provided in Table A.5. For NPV and PV system size, the p-values were found to be less than the $5 \%$ significance level for both test cases Low/Medium and Medium/High. Therefore, the null hypothesis was rejected leading to the conclusion that the mean optimal system size of medium consumers is larger than that of low customers, and less than that of high consumers based on the box plot trends, i.e. the average size for the PV systems is larger for households that consume more energy. However, given the large sample variance evidenced by the wide interquartile ranges summarized in Table 2 particularly for high consumption customers, no prescriptive PV system size can be established for each consumption category. Thus a process to optimally select as PV system, such as the one explored in this article, must be undertaken to avoid uneconomical system selection.

Fig. 7(c) summarizes the savings potential achieved through correct retail electricity plan selection. The metric represents the difference in NPV between a system optimized for the highest cost energy plan and the lowest cost (optimal) plan given a customer's particular energy profile. Based on the magnitude of potential savings, the

Table 2

Summary of median values and associated inter-quartile (IQR) ranges for key economic metrics for each energy consumption range in Newcastle.

\begin{tabular}{cccc}
\hline \multirow{2}{*}{ Metric } & \multicolumn{3}{c}{ Median (IQR) } \\
& Low & Medium & High \\
\hline NPV (\$) & $1,471(1,166)$ & $3,230(1,264)$ & $6,269(2,647)$ \\
Size (kW) & $1.38(0.75)$ & $2.88(0.88)$ & $5.26(1.88)$ \\
Plan Savings (\$) & $829(423)$ & $1,269(1,365)$ & $1,969(2,564)$ \\
MIRR (\%) & $6.02(0.59)$ & $6.15(0.59)$ & $6.34(0.72) \%$ \\
Payback (years) & $12.1(2.5)$ & $11.5(2.6)$ & $10.5(3.0)$ \\
\hline
\end{tabular}



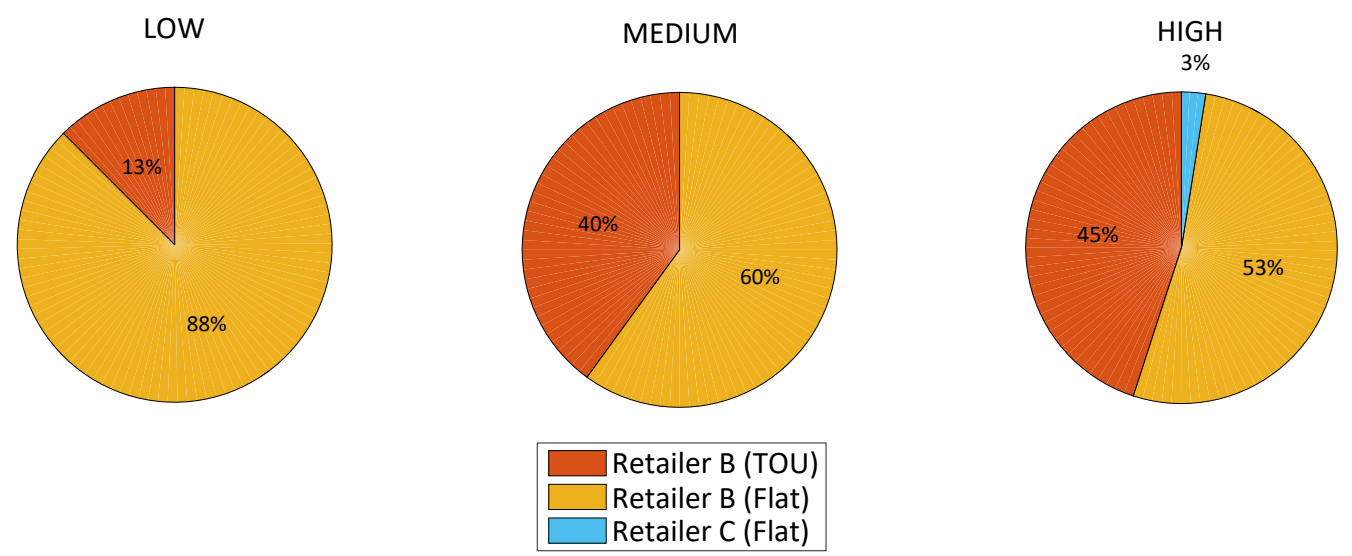

Fig. 6. Proportion of lowest cost energy retailers for Newcastle residences with low, medium and high energy consumption. Note: total percentages are greater than $100 \%$ for the low and high energy charts due to rounding error.

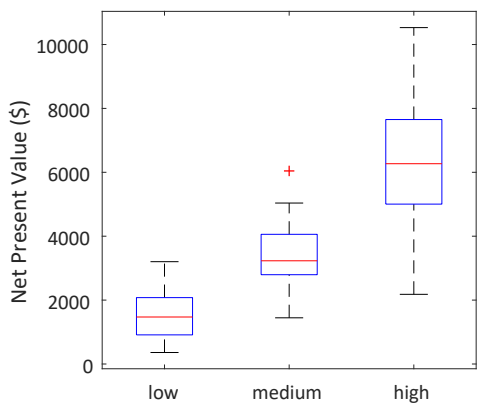

(a)

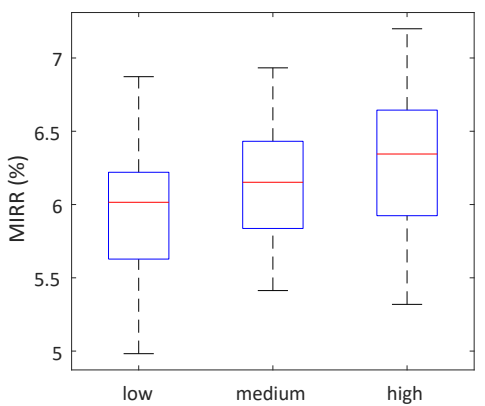

(d)

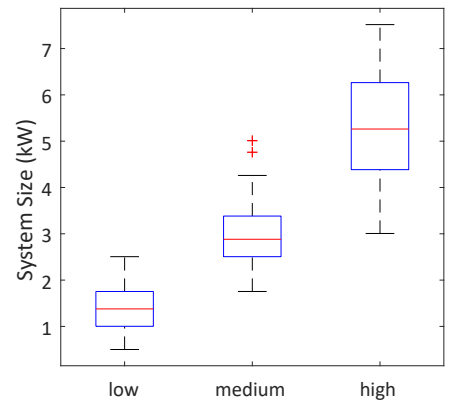

(b)

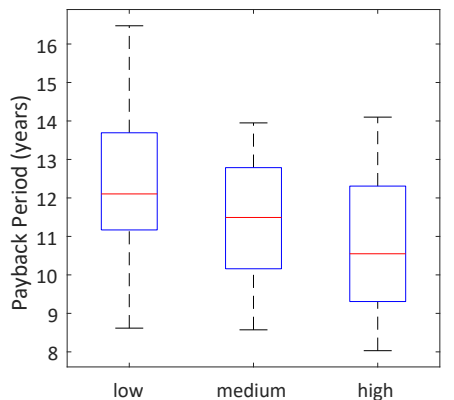

(e)

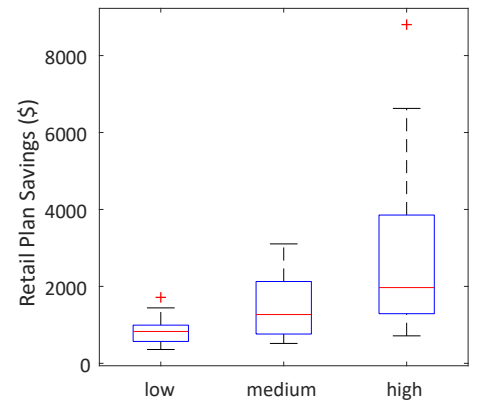

(c)

Fig. 7. Box plots for (a) NPV,(b) system size, (c) plan selection savings, (d) MIRR and (e) Payback period for Newcastle residences with low, medium and high energy consumption profiles.

importance of correct plan selection (achieved through detailed consideration of a customer's particular circum- 865 stances) is clearly evident. Referring to the median values summarized in Table 2 , potential savings were found to be in the range of $31 \%$ (high energy) to $56 \%$ (low energy) relative to the median achievable NPV. Conse- quently, it can be concluded that correct plan selection is a critical consideration to be made in conjunction with optimal selection of the PV system's size and orientation.

As previously mentioned in Section 2.3, despite the obvious net benefit achievable through the installation of $\mathrm{PV}, \mathrm{MIRR}$ is also a key consideration when establishing 
Table 3

Proportion of Newcastle customers where PV is financially attractive (acceptable MIRR).

\begin{tabular}{ccc}
\hline Energy Consumption & MIRR $>6 \%$ & MIRR $>5.5 \%$ \\
\hline Low & $53 \%$ & $88 \%$ \\
Medium & $63 \%$ & $98 \%$ \\
High & $65 \%$ & $88 \%$ \\
\hline All & $60 \%$ & $91 \%$ \\
\hline
\end{tabular}

the viability of the investment. Referring to Fig. 77d), the MIRR ranges observed for the three consumption categories were very similar, with a marginal increase in median MIRR as consumption increased. However significant overlap in the inter-quartiles ranges signals difficulty in establishing a clear differentiator between the distributions. Indeed when conducting hypothesis testing on the mean of the MIRR distributions, as summarized in Table A.5, the null hypotheses could not be rejected at the 5\% significance level. Consequently, no assertions could be made regarding differences in the 930 MIRRs between the consumption categories.

Based on the MIRR metric, investing in PV was found to be a 'non-viable' financial investment option for a large proportion of customers. Referring to Table 3 .

885 overall only $60 \%$ of customers were found to have a return on investment above $6 \%$ for an optimized PV system. However relaxation of the MIRR may be considered acceptable for many customers given the intangible value associated with PV systems. After relaxing the acceptable MIRR rate to $5.5 \%$, the proportion of customers with 'viable' PV investment options increased to $91 \%$.

Referring to Fig. 7(e), slightly shorter median payback periods were observed as the energy consumption increased. However similar to MIRR, no differences could be conclusively established between the payback periods of medium and high customers due to a failure to reject the null hypotheses. However the null hypothesis was rejected at the 5\% level for the low and medium comparison. Consequently, it can be concluded that the mean payback period is less for consumers with medium and high energy consumption than that of low consumers. From a population perspective, customers with a higher relative energy consumption profile are more likely to achieve an earlier payback on their investment.

${ }_{905}$ Despite all customer achieving investment payback 955 prior to the assumed system end-of-life (20 years), a number of installations were found to have payback periods in excess of 14 years. Such a period may be unacceptably long for many investors. Shorter payback periods on the system lifetime prior to optimization. Such a lifetime constraint will result in a different PV system size and orientation, ultimating yielding a lower NPV compared to the 20 year period considered in this research. 915 wer if the investor intends to relocate after a predetermined period, thereby foregoing the residual value in the PV system, such a consideration is justifiable.

The higher NPVs coupled with shorter payback periods observed in this section indicate households with igher energy consumption have a greater justification to install a PV system, an relatively intuitive expectation. However the results also suggest that under Australian regulatory environments and incentive schemes, PV system optimization becomes increasingly important for households with lower energy consumption to avoid ineffective system selection. The lower NPVs seen for low energy households, indicate a higher sensitivity to sub-optimal sizing, potentially removing the viability of PV altogether without due assessment.

\subsection{Other Locations}

To gain a wider appreciation of the optimized economic performance characteristics of PV systems, the optimization strategy was applied to four additional Australian locations. As the state of New South Wales has three electricity distributors, the investigation was extended to hypothetical customers from the cities of Tamworth and Parramatta within the other two networks to complement the investigation in Section 3.2. Furthermore, the cities of Melbourne and Brisbane, in the states of Victoria and Queensland respectively, were also investigated due to their geographic and regulatory separation from New South Wales. As smart meter data for the other locations were not available for this research, the data for the same 120 customers used in the Newcastle analysis were again applied. It should be noted that the assumption of homogeneous load profiles between the different locations has inherent shortcomings as the average load profile for the Newcastle area does not necessarily translate to the other locations. However the analysis methodology remains valid and it is conceivable that similar load profiles may be individually observed in different locations.

A summary of the mean economic performance and system characteristics for optimized systems in each location is provided in Table 4 Brisbane exhibited the greatest plan diversity with four of the six plans assessed and a mixture of TOU and flat tariffs, featuring as the lowest cost plan. In contrast, Tamworth customers received the greatest benefit from TOU tariff structures only, with the vast majority from Retailer A (97.5\%). For all locations 
Table 4

Comparison of mean economic performance and system characteristics for optimized PV systems in different locations. Note: the total proportion of electricity plans is greater than $100 \%$ in some instances due to rounding error.

\begin{tabular}{|c|c|c|c|c|c|c|c|c|c|c|c|c|}
\hline \multirow{2}{*}{ Location } & \multicolumn{2}{|c|}{$\mathrm{A}$} & \multicolumn{2}{|c|}{ B } & \multicolumn{2}{|c|}{$\mathrm{C}$} & \multirow{2}{*}{ NPV } & \multirow{2}{*}{$\begin{array}{l}\text { Size } \\
(\mathrm{kW})\end{array}$} & \multirow{2}{*}{$\begin{array}{c}\text { CER Data } \\
(\mathrm{kW})\end{array}$} & \multirow{2}{*}{$\begin{array}{c}\text { Plan } \\
\text { Savings }\end{array}$} & \multirow{2}{*}{$\begin{array}{c}\text { Payback } \\
\text { (Years) }\end{array}$} & \multirow{2}{*}{$\begin{array}{l}\text { MIRR } \\
>6 \%\end{array}$} \\
\hline & TOU & Flat & TOU & Flat & TOU & Flat & & & & & & \\
\hline Newcastle & - & - & $32.5 \%$ & $66.7 \%$ & - & $0.8 \%$ & $\$ 3,741$ & 3.22 & 5.41 & $\$ 1,632$ & 12.3 & $60 \%$ \\
\hline Brisbane & - & $7.5 \%$ & $54.2 \%$ & - & $31.7 \%$ & $6.7 \%$ & $\$ 4,418$ & 3.68 & 5.74 & $\$ 1,295$ & 11.9 & $69.2 \%$ \\
\hline Melbourne & - & $20 \%$ & $80 \%$ & - & - & - & $\$ 3,803$ & 2.72 & 4.42 & $\$ 2,374$ & 11.7 & $75 \%$ \\
\hline Parramatta & - & $86.7 \%$ & $0.8 \%$ & - & $12.5 \%$ & - & $\$ 3,699$ & 3.30 & 5.68 & $\$ 1,972$ & 12.5 & $58.3 \%$ \\
\hline Tamworth & $97.5 \%$ & - & $2.5 \%$ & - & - & - & $\$ 5,545$ & 4.06 & 5.83 & $\$ 3,772$ & 11.3 & $77.5 \%$ \\
\hline
\end{tabular}

assessed, the achievable savings through correct plan se- 1000 lection prior to system optimization are significant. For Brisbane customers, plan savings of $\$ 1,295$ on average were observed while savings of $\$ 3,772$ were possible in Tamworth.

Referring to the NPV column, the mean net benefit achievable through system optimization varied significantly amongst the five locations. Comparing the highest NPV city of Tamworth with the lowest NPV city of Parramatta, customers with the sampled load profiles would on average receive an additional benefit of $\$ 1,846$.

The proportion of customers with 'viable' PV investment opportunities also varied between the locations ${ }_{1010}$ assessed. Parramatta exhibited the lowest with $58.3 \%$ of customers having 'viable' opportunities whereas Tamworth exhibited the greatest proportion at $77.5 \%$. Interestingly, a relatively high proportion of customers in Melbourne were found to have a 'viable' PV investment. ${ }_{1015}$ Although not demonstrated in this article, Melbourne has ${ }_{980}$ the lowest historical average insolation levels amongst the locations assessed. Consequently the intuitive assumption would be to expect a lower PV investment value. However through a combination of optimal PV system selection and comparatively high prevailing retail 985 electricity costs, PV systems were found to be a 'viable' investment for $75 \%$ of the hypothetical Melbourne customers assessed.

The mean installed system sizes for the locations as- 1025 sessed from January 2015 to August 2016 are also provided in Table 4 based on CER data [2]. A comparison between the mean optimized PV sizes found in this research and the historical CER data shows significant over-sizing for each of the locations assessed, approxi- 1030 mately $2 \mathrm{~kW}$ on average. This conclusion can be drawn as no significant policy changes have been made relating to small-scale PV systems since 2011-2012. Therefore the systems installed in 2015-2016 were exposed to identical incentives to those considered in the optimization 1035 problem investigated in this article. These results corrob- orate the size reduction forecasts of the SGSC project [4] and the Grattan Institute [5].

\section{Conclusion}

The introduction of smart grid technologies and the phased removal of incentive schemes is likely to further complicate the cost-effective selection and integration of residential PV systems in the future. The continued increase in smart meter market penetration allows high temporal resolution data to be leveraged by electricity customers in order to make informed PV investment decisions. Consequently an optimization tool is required to maximize the investment value of PV systems and avoid ineffective capital spending.

In this article, such an optimization strategy was explored. Models for hourly solar insolation and PV energy production, as well as underlying economic models based on a net present value analysis, were defined as key components of the optimization objective function.

An algorithm based on a canonical particle swarm optimization was modified to include a penalty function to enable the handling of parameter constraints. A hypercube nearest-vertex approach was incorporated to facilitate the inclusion of discrete parameters such as the number of PV modules in the system.

The optimization methodology was tested in an Australian context, using real-world hourly smart meter and insolation data applied to currently available incentive schemes and retail electricity plans.

With realistically defined economic parameters, a positive NPV was achievable for all customers assessed. Net present value, system size and savings achievable through correct retail plan selection were all found to increase between the low, medium and high annual electricity consumption brackets defined in the article. However 'viable' PV investment opportunities were not universally observed for all customers, with at most $77.5 \%$ of customers amongst the locations assessed yielding a 
return greater than the cost of capital. A wide variety of optimal retail plans was observed, from the extreme of $97.5 \%$ from one retailer in one city to a diverse array of

ans and tariffs structures in others.

A sensitivity analysis on individual customers demonstrated the significant negative impact of non-optimal sizing on the value of the investment, particularly for over-sized systems. However a sensitivity analysis conthe on tilt and azimuth found limited effect on the net benefit for deviations within $\pm 10^{\circ}$ and $\pm 20^{\circ}$ respectively. Furthermore, optimal azimuth selection was found to contribute to less than $1 \%$ of the potential net benefit for flat tariffs and just 5\% for time-of-use tariffs. Conequently, azimuth was therefore deemed non-critical and the optimization problem can be reduced to the two dimensions of tilt and size.

Finally, the average optimal system sizes for the customers and locations assessed were found to be signifcantly less than the average size installed in 2015 and 2016, approximately $2 \mathrm{~kW}$ on average. The observed disparity between current practices of the Australian residential PV industry and the characteristics of the optimized systems found in this article highlights the 1090 necessity for an economic optimization strategy to be routinely implemented prior to the decision to invest.

Modification of the optimization strategy to include other disruptive technologies and ancillary service opportunities, such as energy storage and demand response strategies, is currently the subject of further research by the authors.

\section{Appendix A. Hypothesis Tests}

The hypothesis testing methodology used in this article is based on the p-value approach detailed in Rice [49]. While hypothesis testing is usually established on the assumption of normally distributed populations with equal variance, if the sample sizes are sufficiently large for distributions exhibiting non-normal characteristics, such as skewness and unequal variance as apparent in 1095 dard hypothesis testing methodology remains valid [49]. As the samples considered in this research each include 40 customers, the sample sizes are deemed sufficiently large to invoke the above statement.

Under the well defined p-value approach for the twotailed $t$-test, if the p-value calculated for the sample test statistic $t^{*}$ is less than the confidence level $\alpha$ (assumed to be $5 \%$ in this research), the null hypothesis (equal distribution means) is rejected, in favour of the alternative 1105 hypothesis (distribution means are not equal).
The results of the hypothesis tests undertaken for the analysis in Section 3.2 are summarized in Table A.5

Table A.5

Summary of hypothesis tests for distributions of key performance and system metrics.

\begin{tabular}{cccc}
\hline Tested Samples & Metric & p-value & $\begin{array}{c}\text { Reject Null Hyp. } \\
(@ \alpha=5 \%)\end{array}$ \\
\hline \multirow{4}{*}{ Low/Medium $\alpha=$ Yes } \\
& NPV & $2.79 \times 10^{-14}$ & Yes \\
& Size & $1.63 \times 10^{-17}$ & Yes \\
& MIRR & 0.0818 & No \\
& Payback & 0.0298 & Yes \\
\hline \multirow{5}{*}{ Medium/High } & NPV & $8.45 \times 10^{-13}$ & Yes \\
& Size & $7.07 \times 10^{-15}$ & Yes \\
& Savings & $3.31 \times 10^{-4}$ & Yes \\
& MIRR & 0.2109 & No \\
& Payback & 0.1075 & No \\
\hline
\end{tabular}

\section{Appendix B. PV module characteristics}

The key PV module parameters required for this research are summarized in Table B.6 based on Trina Solar's TSM-250PD05.05 model module.

Table B.6

Key parameters for Trina TSM-250PD05.05 PV module.

\begin{tabular}{lc}
\hline Parameter & Value \\
\hline Maximum Power Voltage $\left(V_{m p p}\right)$ & $30.3 \mathrm{~V}$ \\
Maximum Power Current $\left(I_{m p p}\right)$ & $8.27 \mathrm{~A}$ \\
Maximum Power $\left(P_{\max }\right)$ & $250.58 \mathrm{~W}$ \\
Module Efficiency $\left(\eta_{\operatorname{mpp}}\right)$ & $15.3 \%$ \\
Temp. coefficient of $P_{\max }\left(\mu_{m p p}\right)$ & $-0.41 \% /{ }^{\circ} \mathrm{C}$ \\
Nominal Operating Cell Temp. $\left(T_{N O C T}\right)$ & $44^{\circ} \mathrm{C}$ \\
Area $\left(A_{c}\right)$ & $1.637 \mathrm{~m}^{2}$ \\
\hline
\end{tabular}

\section{Appendix C. Retail Electricity Tariffs}

The electricity tariffs assumed in this article are based on the standing offers available from Origin Energy, EnergyAustralia and AGL in September 2016. The flat tariff retail plans assumed in this article are summarized in Table C.7. In principal under a flat tariff plan, each unit of energy at any time of day is charged uniformly at a single rate. However a number of flat tariff plan considered in this analysis also include incremental flat tariff increase based on total daily or quarterly energy consumption. The flat tariffs associated with each incremental energy block are shown in Table C.8

The TOU tariff retail plans assumed are summarized in Table C.9 and the times for which each TOU tariff level is applicable are shown in Table C.10. 
Table C.7

Flat tariffs for each retail plan and location considered.

\begin{tabular}{ccccccc}
\hline \multirow{2}{*}{ Retailer } & Location & $\begin{array}{c}\text { Flat Tariff 1 } \\
(\mathrm{c} / \mathrm{kWh})\end{array}$ & $\begin{array}{c}\text { Flat Tariff 2 } \\
(\mathrm{c} / \mathrm{kWh})\end{array}$ & $\begin{array}{c}\text { Flat Tariff 3 } \\
(\mathrm{c} / \mathrm{kWh})\end{array}$ & $\begin{array}{c}\text { Daily Supply } \\
\text { Charge (c/Day) }\end{array}$ & $\begin{array}{c}\text { Feed-in Tariff } \\
(\mathrm{c} / \mathrm{kWh})\end{array}$ \\
\hline \multirow{5}{*}{ Origin Energy } & Newcastle & 27.005 & 26.51 & 24.20 & 88.66 & 6.0 \\
& Parramatta & 25.773 & 25.113 & 23.903 & 86.35 & 6.0 \\
& Tamworth & 26.62 & 26.191 & 25.773 & 149.60 & 6.0 \\
& Melbourne & 27.654 & - & - & 108.757 & 5.0 \\
& Brisbane & 25.586 & - & - & 128.117 & 6.0 \\
\hline \multirow{5}{*}{ EnergyAustralia } & Ausgrid & 26.72571 & 26.1217 & 25.52869 & 83.9025 & 6.1 \\
& Endeavour Energy & 28.02481 & 27.05923 & 25.20859 & 89.7644 & 6.1 \\
& Essential Energy & 30.31237 & 29.74906 & 29.22029 & 152.6767 & 6.1 \\
& Jemena & 27.654 & - & - & 115.50 & 5.0 \\
& Energex & 25.982 & - & - & 128.70 & 6.0 \\
\hline \multirow{6}{*}{ AGL } & Ausgrid & 27.621 & 26.818 & 20.911 & 86.427 & 6.1 \\
& Endeavour Energy & 27.104 & 26.587 & 26.367 & 85.217 & 6.1 \\
& Essential Energy & 29.909 & 29.458 & 29.018 & 148.918 & 6.1 \\
& Jemena & 27.225 & - & - & 120.868 & 5.0 \\
& Energex & 27.071 & - & - & 115.236 & 6.0 \\
\hline
\end{tabular}

Table C.8

Energy blocks associated with each flat tariff rate for each retail electrcity plan.

\begin{tabular}{|c|c|c|c|c|}
\hline Retailer & Location & Flat Tariff 1 & Flat Tariff 2 & Flat Tariff 3 \\
\hline \multirow{5}{*}{ Origin Energy } & Newcastle & First $10.9589 \mathrm{kWh} / \mathrm{Day}$ & Next 10.9589 kWh/Day & remaining kWh/Day \\
\hline & Parramatta & First $10.9589 \mathrm{kWh} /$ Day & Next 8.2192 kWh/Day & remaining kWh/Day \\
\hline & Tamworth & First $10.9589 \mathrm{kWh} /$ Day & Next 8.2192 kWh/Day & remaining kWh/Day \\
\hline & Melbourne & All kWh/Day & - & - \\
\hline & Brisbane & All kWh/Day & - & - \\
\hline \multirow{5}{*}{ EnergyAustralia } & Newcastle & First $10.9589 \mathrm{kWh} /$ Day & Next 10.9589 kWh/Day & remaining kWh/Day \\
\hline & Parramatta & First $10.9589 \mathrm{kWh} /$ Day & Next 8.2192 kWh/Day & remaining kWh/Day \\
\hline & Tamworth & First 10.989 kWh/Day & Next 8.2418kWh/Day & remaining kWh/Day \\
\hline & Melbourne & All kWh/Day & - & - \\
\hline & Brisbane & All kWh/Day & - & - \\
\hline \multirow{5}{*}{ AGL } & (Newcastle) & First $1000 \mathrm{kWh} /$ Quarter & Next 1000 kWh/Quarter & remaining $\mathrm{kWh} / \mathrm{Quarter}$ \\
\hline & (Parramatta) & First $1000 \mathrm{kWh} /$ Quarter & Next 750 kWh/Quarter & remaining $\mathrm{kWh} / \mathrm{Quarter}$ \\
\hline & (Tamworth) & First $1000 \mathrm{kWh} /$ Quarter & Next 750 kWh/Quarter & remaining $\mathrm{kWh} /$ Quarter \\
\hline & Melbourne & All kWh/Quarter & - & - \\
\hline & Brisbane & All kWh/Quarter & - & - \\
\hline
\end{tabular}


Table C.9

TOU tariffs for each retail plan and location considered.

\begin{tabular}{ccccccc}
\hline \multirow{2}{*}{ Retailer } & Location & $\begin{array}{c}\text { Flat Tariff 1 } \\
(\mathrm{c} / \mathrm{kWh})\end{array}$ & $\begin{array}{c}\text { Flat Tariff 2 } \\
(\mathrm{c} / \mathrm{kWh})\end{array}$ & $\begin{array}{c}\text { Flat Tariff 3 } \\
(\mathrm{c} / \mathrm{kWh})\end{array}$ & $\begin{array}{c}\text { Daily Supply } \\
\text { Charge }(\mathrm{c} / \text { Day })\end{array}$ & $\begin{array}{c}\text { Feed-in Tariff } \\
(\mathrm{c} / \mathrm{kWh})\end{array}$ \\
\hline \multirow{5}{*}{ Origin } & Newcastle & 52.80 & 21.45 & 13.20 & 99.00 & 6.0 \\
& Parramatta & 35.31 & 29.15 & 15.40 & 108.90 & 6.0 \\
& Tamworth & 31.35 & 31.35 & 18.15 & 149.60 & 6.0 \\
& Melbourne & 46.453 & 28.567 & 20.284 & 108.757 & 5.0 \\
& Brisbane & 33.803 & 24.365 & 19.767 & 128.117 & 6.0 \\
\hline \multirow{5}{*}{ EnergyAustralia } & Newcastle & 53.98844 & 21.62446 & 12.03719 & 95.6494 & 6.1 \\
& Parramatta & 38.1634 & 28.39265 & 14.3803 & 112.5366 & 6.1 \\
& Tamworth & 33.62293 & 33.62293 & 17.00116 & 153.1365 & 6.1 \\
& Melbourne & 35.222 & - & 17.842 & 113.30 & 5.0 \\
& Brisbane & 35.20 & 24.53 & 17.897 & 128.70 & 6.0 \\
\hline \multirow{5}{*}{ AGL } & Newcastle & 55.363 & 21.659 & 12.177 & 96.426 & 6.1 \\
& Parramatta & 36.245 & 29.70 & 14.465 & 109.439 & 6.1 \\
& Tamworth & 34.892 & 34.892 & 18.656 & 148.885 & 6.1 \\
& Melbourne & 34.727 & 27.225 & 20.559 & 120.615 & 5.0 \\
& Brisbane & 35.871 & 25.85 & 21.065 & 115.236 & 6.0 \\
\hline
\end{tabular}

Table C.10

Hours of the day defining off-peak, shoulder and peak periods for each retail electricity plan. WD and WE denote weekday and weekend respectively.

\begin{tabular}{|c|c|c|c|c|}
\hline Retailer & Distributor & Peak Period & Shoulder Period & Off-peak Period \\
\hline \multirow{5}{*}{ Origin } & Newcastle & $\mathrm{WD}=(2 \mathrm{pm}-8 \mathrm{pm})$ & $\begin{array}{c}\mathrm{WD}=(7 \mathrm{am}-2 \mathrm{pm}, 8 \mathrm{pm}-10 \mathrm{pm}) \\
\mathrm{WE}=(7 \mathrm{am}-10 \mathrm{pm})\end{array}$ & All other times \\
\hline & Parramatta & $\mathrm{WD}=(1 \mathrm{pm}-8 \mathrm{pm})$ & $\begin{array}{c}\mathrm{WD}=(7 \mathrm{am}-1 \mathrm{pm}, 8 \mathrm{pm}-10 \mathrm{pm}) \\
\mathrm{WE}=(7 \mathrm{am}-10 \mathrm{pm})\end{array}$ & All other times \\
\hline & Tamworth & $\mathrm{WD}=(7 \mathrm{am}-9 \mathrm{am}, 5 \mathrm{pm}-8 \mathrm{pm})$ & $\mathrm{WD}=(9 \mathrm{am}-5 \mathrm{pm}, 8 \mathrm{pm}-10 \mathrm{pm})$ & All other times \\
\hline & Melbourne & $\mathrm{WD}=(3 \mathrm{pm}-9 \mathrm{pm})$ & $\begin{array}{c}\mathrm{WD}=(7 \mathrm{am}-3 \mathrm{pm}, 9 \mathrm{pm}-10 \mathrm{pm}) \\
\mathrm{WE}=(7 \mathrm{am}-10 \mathrm{pm})\end{array}$ & All other times \\
\hline & Brisbane & $\mathrm{WD}=(4 \mathrm{pm}-8 \mathrm{pm})$ & $\begin{array}{c}\mathrm{WD}=(7 \mathrm{am}-4 \mathrm{pm}, 8 \mathrm{pm}-10 \mathrm{pm}) \\
\mathrm{WE}=(7 \mathrm{am}-10 \mathrm{pm})\end{array}$ & All other times \\
\hline \multirow{5}{*}{ Energy Australia } & Newcastle & $\mathrm{WD}=(2 \mathrm{pm}-8 \mathrm{pm})$ & $\begin{array}{c}\mathrm{WD}=(7 \mathrm{am}-2 \mathrm{pm}, 8 \mathrm{pm}-10 \mathrm{pm}) \\
\mathrm{WE}=(7 \mathrm{am}-10 \mathrm{pm})\end{array}$ & All other times \\
\hline & Parramatta & $\mathrm{WD}=(1 \mathrm{pm}-8 \mathrm{pm})$ & $\begin{array}{c}\mathrm{WD}=(7 \mathrm{am}-1 \mathrm{pm}, 8 \mathrm{pm}-10 \mathrm{pm}) \\
W E=(7 \mathrm{am}-10 \mathrm{pm})\end{array}$ & All other times \\
\hline & Tamworth & $\mathrm{WD}=(7 \mathrm{am}-9 \mathrm{am}, 5 \mathrm{pm}-8 \mathrm{pm})$ & $\mathrm{WD}=(9 \mathrm{am}-5 \mathrm{pm}, 8 \mathrm{pm}-10 \mathrm{pm})$ & All other times \\
\hline & Melbourne & $\mathrm{WD}=(7 \mathrm{am}-11 \mathrm{pm})$ & - & All other times \\
\hline & Brisbane & $\mathrm{WD}=(4 \mathrm{pm}-8 \mathrm{pm})$ & $\begin{array}{c}\mathrm{WD}=(7 \mathrm{am}-4 \mathrm{pm}, 8 \mathrm{pm}-10 \mathrm{pm}) \\
\mathrm{WE}=(7 \mathrm{am}-10 \mathrm{pm})\end{array}$ & All other times \\
\hline \multirow{5}{*}{ AGL } & Newcastle & $\mathrm{WD}=(2 \mathrm{pm}-8 \mathrm{pm})$ & $\begin{array}{c}\mathrm{WD}=(7 \mathrm{am}-2 \mathrm{pm}, 8 \mathrm{pm}-10 \mathrm{pm}) \\
\mathrm{WE}=(7 \mathrm{am}-10 \mathrm{pm})\end{array}$ & All other times \\
\hline & Parramatta & $\mathrm{WD}=(1 \mathrm{pm}-8 \mathrm{pm})$ & $\mathrm{WD}=(7 \mathrm{am}-1 \mathrm{pm}, 8 \mathrm{pm}-10 \mathrm{pm})$ & All other times \\
\hline & Tamworth & $\mathrm{WD}=(7 \mathrm{am}-9 \mathrm{am}, 5 \mathrm{pm}-8 \mathrm{pm})$ & $\mathrm{WD}=(9 \mathrm{am}-5 \mathrm{pm}, 8 \mathrm{pm}-10 \mathrm{pm})$ & All other times \\
\hline & Melbourne & $\mathrm{WD}=(3 \mathrm{pm}-9 \mathrm{pm})$ & $\begin{array}{c}\mathrm{WD}=(7 \mathrm{am}-3 \mathrm{pm}, 9 \mathrm{pm}-10 \mathrm{pm}) \\
\mathrm{WE}=(7 \mathrm{am}-10 \mathrm{pm})\end{array}$ & All other times \\
\hline & Brisbane & $\mathrm{WD}=(4 \mathrm{pm}-8 \mathrm{pm})$ & $\begin{array}{c}\mathrm{WD}=(7 \mathrm{am}-4 \mathrm{pm}, 8 \mathrm{pm}-10 \mathrm{pm}) \\
\mathrm{WE}=(7 \mathrm{am}-10 \mathrm{pm})\end{array}$ & All other times \\
\hline
\end{tabular}




\section{Acknowledgements}

This research is supported by an Australian Government Research Training Program Scholarship.

\section{References}

[1] Solar feed-in tariffs in 2016-17, Report, Independent Pricing and Regulatory Tribunal (June 2016).

[2] Australian Government Clean Energy Regulator, Postcode data for small-scale installations (2016).

1115 http://www.cleanenergyregulator. gov.au/DocumentAssets/Pages/ Postcode-data-for-small-scale-installations. aspx

[3] Australian Government Climate Change Authority, Renewable energy target review, Report (December 2014).

[4] M. Norris, R. Cliff, R. Sharp, S. Koci, H. Gardner, Smart Grid, Smart City: Shaping Australia's energy future national cost benefit assessment, Report, Arup (July 2014).

[5] T. Wood, D. Blowers, C. Chisholm, Sundown, sunrise: How Australia can finally get solar power right, Report 2015-2, Grattan ${ }^{11}$ Institute, (May 2015).

[6] A. K. Yadav, S. S. Chandel, Tilt angle optimization to maximize incident solar radiation: A review, Renewable and Sustainable Energy Reviews 23 (2013) 503--513. doi:10.1016/j.rser 2013.02.027

[7] T. Khatib, I. A. Ibrahim, A. Mohamed, A review on sizing methodologies of photovoltaic array and storage battery in a standalone photovoltaic system, Energy Conversion and Management 120 (2016) 430--448. doi:10.1016/j.enconman. 2016.05.011

[8] J. D. Rhodes, C. R. Upshaw, W. J. Cole, C. L. Holcomb, M. E. Webber, A multi-objective assessment of the effect of solar PV array orientation and tilt on energy production and system economics, Solar Energy 108 (0) (2014) 28--40. doi:10.1016/j.solener.2014.06.032

[9] J. Widen, E. Wackelgard, P. D. Lund, Options for improving the load matching capability of distributed photovoltaics: Methodology and application to high-latitude data, Solar Energy 83 (11) (2009) 1953--1966. doi:10.1016/j . solener.2009 07.007

[10] T. Beck, H. Kondziella, G. Huard, T. Bruckner, Assessing the influence of the temporal resolution of electrical load and PV generation profiles on self-consumption and sizing of PV-battery

systems, Applied Energy 173 (2016) 331--342. doi:10.1016/

1150 j.apenergy.2016.04.050

[11] G. Merei, C. Berger, D. U. Sauer, Optimization of an off-grid hybrid PV-wind-diesel system with different battery technologies

u using genetic algorithm, Solar Energy 97 (2013) 460--473. doi : 10.1016/j.solener.2013.08.016

[12] A. Gonzlez, J.-R. Riba, A. Rius, R. Puig, Optimal sizing ${ }^{1220}$ of a hybrid grid-connected photovoltaic and wind power system, Applied Energy 154 (2015) 752--762. doi:10.1016/j apenergy.2015.04.105

[13] C. Koo, T. Hong, M. Lee, J. Kim, An integrated multi-objective optimization model for determining the optimal solution in im- ${ }^{12}$ plementing the rooftop photovoltaic system, Renewable and Sus-

1 tainable Energy Reviews 57 (2016) 822--837. doi:10.1016/j. rser.2015.12.205

[14] B. Zhao, X. Zhang, P. Li, K. Wang, M. Xue, C. Wang, Optimal sizing, operating strategy and operational experience of a ${ }^{12}$ stand-alone microgrid on dongfushan island, Applied Energy
113 (2014) 1656--1666. doi:10.1016/j.apenergy.2013 09.015

[15] Y.-P. Chang, Optimal the tilt angles for photovoltaic modules using PSO method with nonlinear time-varying evolution, Energy 35 (5) (2010) 1954--1963. doi:10.1016/j .energy . 2010.01 010

[16] A. Khare, S. Rangnekar, A review of particle swarm optimization and its applications in solar photovoltaic system, Applied Soft Computing 13 (5) (2013) 2997--3006. doi:10.1016/j .asoc 2012.11.033

[17] A. K. Bansal, R. A. Gupta, R. Kumar, Optimization of hybrid $\mathrm{PV} /$ wind energy system using meta particle swarm optimization (MPSO), in: India International Conference on Power Electronics 2010 (IICPE2010), pp. 1--7. doi:10.1109/IICPE. 2011. 5728079

[18] Y. S. Zhao, J. Zhan, Y. Zhang, D. P. Wang, B. G. Zou, The optimal capacity configuration of an independent wind/pv hybrid power supply system based on improved PSO algorithm, in: Advances in Power System Control, Operation and Management (APSCOM 2009), 8th International Conference on, pp. 1--7. doi:10.1049/cp.2009.1806

[19] M. Bashir, J. Sadeh, Size optimization of new hybrid standalone renewable energy system considering a reliability index, in: Environment and Electrical Engineering (EEEIC), 2012 11th International Conference on, pp. 989--994. doi:10.1109/EEEIC 2012.6221521

[20] X. Han, H. Zhang, X. Yu, L. Wang, Economic evaluation of gridconnected micro-grid system with photovoltaic and energy storage under different investment and financing models, Applied Energy 184 (2016) 103--118. doi:10.1016/j.apenergy. 2016. 10.008

[21] J. Chen, H. E. Garcia, Economic optimization of operations for hybrid energy systems under variable markets, Applied Energy 177 (2016) 11--24. doi:10.1016/j.apenergy.2016 05.056

[22] G. Merei, J. Moshvel, D. Magnor, D. U. Sauer, Optimization of self-consumption and techno-economic analysis of PV-battery systems in commercial applications, Applied Energy 168 (2016) 171--178. doi:10.1016/j.apenergy.2016.01.083

[23] G. Mulder, D. Six, B. Claessens, T. Broes, N. Omar, J. V. Mierlo, The dimensioning of PV-battery systems depending on the incentive and selling price conditions, Applied Energy 111 (2013) 1126--1135. doi:10.1016/j.apenergy.2013.03.059

[24] B. Del Fabbro, A. Valentincic, A. F. Gubina, An adequate required rate of return for grid-connected PV systems, Solar Energy 132 (2016) 73--83. doi:10.1016/j.solener.2016.03.006

[25] G. G. Pillai, G. A. Putrus, T. Georgitsioti, N. M. Pearsall, Near-term economic benefits from grid-connected residential PV (photovoltaic) systems, Energy 68 (2014) 832--843. doi : 10.1016/j.energy.2014.02.085

[26] R. Bakhshi, J. Sadeh, A comprehensive economic analysis method for selecting the PV array structure in grid-connected photovoltaic systems, Renewable Energy 94 (2016) 524 -- 536. doi:10.1016/j.renene.2016.03.091

[27] B. P. Numbi, S. J. Malinga, Optimal energy cost and economic analysis of a residential grid-interactive solar PV system- case of eThekwini municipality in South Africa, Applied Energy 186, Part 1 (2017) 28--45. doi:10.1016/j . apenergy .2016.10 048

[28] J. Every, L. Li, Y. G. Guo, D. G. Dorrell, Maximizing investment value of small-scale pv in a smart grid environment, in: 2016 IEEE International Conference on Renewable Energy Research and Applications (ICRERA), Birmingham, United Kingdom, 2016, pp. 385--390. doi:10.1109/ICRERA. 2016.7884366

[29] GeoModel Solar, SolarGIS version 1.8: Specifications of solar 
radiation and meteo database, Report (18 March 2013).

[30] J. Remund, S. Mller, S. Kunz, B. Huguenin-Landl, C. Studer, D. Klauser, C. Schilter, R. Lehnherr, Meteonorm global meteorological database handbook part II: Theory, version 7.1, Report 1300 (July 2015).

[31] Australian Government Bureau of Meteorology, Climate data online (2016). http://www.bom.gov.au/climate/data/

[32] D. G. Erbs, S. A. Klein, J. A. Duffie, Estimation of the diffuse radiation fraction for hourly, daily and monthly-average global radiation, Solar Energy 28 (4) (1982) 293--302. doi : 10.1016/ 0038-092X (82) 90302-4

[33] J. A. Duffie, W. A. Beckman, Solar engineering of thermal processes, Vol. 4th, Wiley, Hoboken, N.J., 2013.

[34] M. Collares-Pereira, A. Rabl, The average distribution of solar radiation-correlations between diffuse and hemispherical and between daily and hourly insolation values, Solar Energy 22 (2) (1979) 155--164. doi : 10.1016/0038-092X (79) 90100-2

[35] B. Y. H. Liu, R. C. Jordan, The interrelationship and characteristic distribution of direct, diffuse and total solar radiation, Solar Energy 4 (3) (1960) 1--19. doi:10.1016/0038-092X(60) 90062-1

[36] A. M. Noorian, I. Moradi, G. A. Kamali, Evaluation of 12 models to estimate hourly diffuse irradiation on inclined surfaces, Renewable Energy 33 (6) (2008) 1406--1412. doi: 10.1016/j.renene.2007.06.027

[37] D. T. Reindl, W. A. Beckman, J. A. Duffie, Evaluation of hourly tilted surface radiation models, Solar Energy 45 (1) (1990) 9--17. doi:10.1016/0038-092X(90)90061-G

[38] Reserve Bank of Australia, Inflation target (2016). http://www.rba.gov.au/inflation/

[39] S. A. Y. Lin, The modified internal rate of return and investment criterion, The Engineering Economist 21 (4) (1976) 237--247. doi:10.1080/00137917608902796

[40] W. Johnston, R. Egan, National survey report of PV power applications in Australia 2015, Report, Australian PV Institute (June 2016).

[41] Australian Bureau of Statistics, 6401.0 - consumer price index, Australia, Sep 2016 (26 Oct 2016 2016).

nttp://www.abs.gov.au/ausstats/abs@.nsf/mf/6401. 0

[42] Australian Government Clean Energy Regulator, Small generation unit stc calculator (2016) https://www.rec-registry.gov.au/rec-registry/ app/calculators/sgu-stc-calculator

[43] J. Sun, C.-H. Lai, X.-J. Wu, Particle swarm optimisation, Chapman and Hall CRC numerical analysis and scientific computing, CRC Press, Boca Raton, Fla., 2012.

[44] J. Kennedy, R. Eberhart, Particle swarm optimization, in: Neural Networks, 1995. Proceedings., IEEE International Conference on, Vol. 4, pp. 1942--1948. doi:10.1109/ICNN.1995.488968

[45] J. Sun, J. Liu, W. Xu, Using quantum-behaved particle swarm optimization algorithm to solve non-linear programming problems, International Journal of Computer Mathematics 84 (2) (2007) 261--272. doi:10.1080/00207160601170254

[46] K. E. Parsopoulos, M. N. Vrahatis, Particle swarm optimization method for constrained optimization problems, Intelligent Technologies - Theory and Application: New Trends in Intelligent Technologies 76 (2002) 214--220.

[47] S. Chowdhury, W. Tong, A. Messac, J. Zhang, A mixed-discrete particle swarm optimization algorithm with explicit diversitypreservation, Structural and Multidisciplinary Optimization 47 (3) (2013) 367--388. doi : 10.1007/s00158-012-0851-z

[48] Australian Government Department of Industry, Innovation and Science;, Smart-grid smart-city customer trial data (2016).
1. https://data.gov.au/dataset/

smart-grid-smart-city-customer-trial-data

[49] J. A. Rice, Mathematical statistics and data analysis, Duxbury advanced series, Thomson/Brooks/Cole, Belmont, CA, 2007. 